\title{
Genetic Profiling: Searching for Novel Genetic Aberrations in Glioblastoma
}

\author{
Pouya Jamshidi and Clark C. Chen \\ Additional information is available at the end of the chapter
}

http://dx.doi.org/10.5772/53387

\section{Introduction}

Glioblastoma multiforme (GBM) is the most common primary brain tumors and remains one of the deadliest of human cancers [1]. The incidence of this cancer is fairly low, with 2-3 cases per 100,000 people in Europe and North America. GBM is slightly more common in whites than in blacks, Latinos, and Asians, with a slight male predominance - M:F ratio of 3:2 [2]. The overall prognosis for GBM has changed little in the past two decades, despite major improvements in neuroimaging, neurosurgery, radiation treatment techniques, adjuvant chemotherapy, and supportive care. Without treatment, the median survival is approximately 3 months [3]. The current standard of care involves maximal surgical resection followed by concurrent radiation and chemotherapy with the DNA alkylating agent temozolomide [4]. Despite this aggressive regimen, the median survival remains approximately 14 months. Thus, meaningful strategies for therapeutic intervention are desperately needed.

The most reliable evidence suggests that glioblastomas originate from cells that give rise to glial cells [5, 6]. The World Health Organization (WHO) classifies these glial-derived tumors into four major categories, namely WHO grade I-IV. The higher grade signifies pathohistologic features of increased malignancy. WHO grade IV glioma is synonymous with glioblastoma [7].

Rigorous scientific investigations over the past three decades indicate that glioblastomas, similar to other cancers, are the stem from collection of genetic alterations. These alterations can present in a variety of forms, including epigenetic alterations, point mutations, translocations, amplification or deletions - resulting in gene modifications. The genetic alteration results in either activation or inactivation of specific gene functions that may contribute to the process of carcinogenesis [8]. Those genes, that when activated, contribute to the development of cancer are often termed proto-oncogenes. The mutated forms of these 
genes are referred to as oncogenes. Conversely, genes that when inactivated contribute to carcinogenesis are generally termed tumor suppressor genes. Although it is well established that central nervous system (CNS) carcinogenesis requires multiple deregulations of the normal cellular circuitry, the exact number and nature of genetic alterations and deregulated signaling pathways required for tumorigenesis remains subject of ongoing scientific investigations [9].

\subsection{Cancer genomic era}

The current decade will likely be remembered, in the history of cancer research, as the decade of cancer genomics. The marriage of technology and annotated specimen collection has culminated to provide us with a glimpse of the complex genomic landscape that underlies cancer pathogenesis. Remarkably, these efforts have demonstrated true collaborative spirits between clinicians and basic science researchers with common goals of furthering translational science.

The Cancer Genome Atlas (TCGA) constitutes the largest of the genomic efforts. It is a comprehensive and coordinated effort to accelerate our understanding of the molecular basis of cancer through the application of genome analysis technologies, including largescale genome sequencing. This is accomplished via cataloguing the genetic and epigenetic changes in the cancer genome, with goals of identifying those responsible for carcinogenesis. The project represents a joint effort of the National Human Genome Research Institute (NHGRI), National Cancer Institute (NCI), the U.S. Department of Health and Human Services, and collects of tumor specimen from major cancer centers spanning across the continental USA. The project aims to provide the genomic profile of 500 specimens of various cancer types using state-of-the-art platforms for sequencing, microRNA, mRNA, single- nucleotide polymorphisms (SNPs), and methylation profiling. TCGA started as a pilot project in 2006 with focus on glioblastoma as the first cancer type for study. With the success of the pilot project, TCGA has committed to expand its efforts to aggressively pursue 20 or more additional cancers. While acknowledging the importance of the TCGA in cancer research, one cannot neglect the value of the pioneering genomic efforts that, in many ways, laid the groundwork for the TCGA [10]. The knowledge to sequence the entire genomes of human tumors including glioblastoma, helps formulating new concepts and principles in tumor cell biology, and enables potential exploitation of these major advances for personalized disease management in oncology.

With advances in genomic profiling and sequencing technology, we are beginning to understand the landscape of the genetic events that accumulate during the neoplastic process. The insights gleamed from these genomic profiling has been instrumental to advancing therapeutic strategy. This chapter will aim to review the existing data with regards to chromosomal aberration, mutations, non-doing sequences, over-expressed mRNA, miRNA dysregulation and will explore the opportunities for major therapeutic developments in the cancer gemonic era. 


\section{Chromosomal aberration}

Chromosomal aberration refers to an abnormality in the structure or number of chromosomal content of a cell. Increasingly, cancer is recognized as a heterogeneous collection of diseases whose initiation and progression are prompted by the aberrant function of genes that govern DNA repair, genome stability, cell proliferation, cell death, adhesion, invasion, angiogenesis in complex cell and tissue microenvironment [11, 12]. In addition to high-resolution chromosome banding and advanced chromosomal imaging technologies, chromosome aberrations in cancer cells can be analyzed with an increasing number of large-scale, comprehensive genomic and molecular genetic technologies. These growing technologies include fluorescence in situ hybridization (FISH) [13, 14], spectral karyotyping (SKY) [13], comparative genomic hybrizidation (CGH) [15, 16], and other highthroughput methods that detects loss of heterzygosity (LOH) [17, 18], in cancer cells such as a new single nucleotide polymorphism arrays (SNP Chips) [19] that detect comprehensive genome-wide copy number changes. With the use of comprehensive molecular technologies, the discovery of the recurrent chromosomal aberrations in cancer is proceeding at a very promising pace. To date, glioblastoma has been subjected to the most extensive genomic profiling of any cancer [20]. Studies carried out over the past three decades suggest that glioblastomas, like other cancers, arise secondary to the accumulation of genetic alterations. These alterations can present as epigenetic modifications, point mutations, translocations, amplifications, or deletions, and modify gene function in ways that dysregulate cellular signaling pathways leading to the cancer phenotype $[11,21]$. While the exact number and nature of genetic alterations and deregulated signaling pathways required for tumorigenesis remains an issue of debate, [9] it is now well understood that central nervous system (CNS) carcinogenesis requires multiple disruptions to the normal cellular circuitry $[22,23]$.

Amongst chromosomal aberrations, amplifications and deletions can be distinguished when considering glioblastoma genesis [24]. Conversely, the reports of incidental translocation are rare in glioblastoma [25]. Thus we will mainly focus our review on chromosomal aberrations that present as amplification or deletion and discuss their contribution in the development of glioblastoma.

\subsection{Amplification}

Amplification of the epidermal growth factor receptor (EGFR) gene is a distinguishing feature in primary glioblastoma [26-28] Moreover, it is now evident that the type of genetic alterations involving EGFR in glioblastoma are distinct from those observed in other EGFRaltered cancers, such as non-small-cell lung cancer (NSCLC). In glioma, focal EGFR amplification occurs at an extremely high level (>20 copies) [20]. Focal (limited to a few $\mathrm{Mb}$ ) and broader (from several Mbs to entire chromosomes) copy number alterations (CNAs) that include the EGFR gene may have different molecular consequences [27]. Focal amplification of EGFR correlates with EGFR over-expression or mutations and deletions in the EGFR gene, and subsequent activation of the PI3K/AKT pathway [27, 29]. Up-regulated 
PI3K/ AKT signaling has been associated with poor prognosis [30]. Evidence of RTK/RAS/PI3K activation has been reported in $88 \%$ of tumors, including contributions from unexpected mutations or deletions in NF1 (18\%) and PIK3R1, which encodes the p85a regulatory subunit of PIK3CA [20].

Furthermore, amplification of the entire chromosome 7 containing EGFR, MET [22] and its ligand HGF has been found to correlate with activation of the MET axis [20,27]. EGFR amplification is reported to appear as double minutes (small fragments of extrachromosomal DNA), and extra copies of EGFR have also been found inserted into different loci on chromosome 7 [31]. Additionally 50\% of EGFR-amplified cells harbor the EGFRvIII mutant, which is an intragenic gene rearrangement generated by an in-frame deletion of exons 2-7 that encode part of the extracellular region [20]. Remarkably, gain of chromosome 7 and amplification of EGFR have been found more frequently in short-term survivors [26, $32]$, however to date EGFR alterations are not thought to be of prognostic importance in glioblastoma $[28,32,33]$.

Amplification of 12q13-15, where the oncogenes CDK4 and MDM2 are located, results in the disruption of both the retinoblastoma (RB) and p53 pathways [22, 27, 34, 35] Specifically, p53 signaling pathway has been reported to be impaired in $87 \%$ of the samples through CDKN2A deletion (49\%), MDM2 (14\%) and MDM4 (7\%) amplification, and mutation and deletion of TP53 (35\%) [20]. Pathway inactivating mutations in the RB pathway were described in glioblastomas prior to the large-scale genomic efforts [23, 36, 37] and the TCGA validated these results and demonstrated that mutations and gene amplifications disrupting RB function are found in approximately $68-80 \%$ of glioblastomas, signifying the critical importance of evading anti-growth signals [21]. RB signaling has been reported to be impaired in $78 \%$ of the samples through CDKN2 family deletion; amplification of CDK4 $(18 \%)$, CDK6 (1\%), and CCND2 (2\%); and mutation or deletion of RB1 (11\%) [20]. Additionally, Genome-Wide Association Studies (GWAS) revealed that single nucleotide polymorphisms (SNPs) in the CDKN2A and CDKN2B have been identified as risk factors for glioma growth [21] [38, 39]. Moreover, the genes encoding the receptor tyrosine kinases KIT, KDR, and PDGFRA, adjacently located on chromosome $4 \mathrm{q} 12$, are frequently found to be (co)amplified [40]. Nearly 30\% of human gliomas show expression patterns that are correlated with PDGFR signaling [41]. For instance, PDGFRA amplification is found in 15\% of all tumors [30, 42]. Of those PDGFRA amplified tumors harboring gene amplification, $40 \%$ harbor an intragenic deletion, termed PDGFRAD8, 9 [43], in which an in-frame deletion of 243 base pairs (bp) of exons 8 and 9 leads to a truncated extracellular domain [44]. Point mutations in PDGFRA are associated with amplification but, unlike EGFR, happen rarely. Elevated AKT phosphorylation has been observed in up to $85 \%$ of glioblastoma cell lines and patient samples [45]. RTK-independent activation of this pathway in glioblastoma can occur via mutation or amplification of PIK3CA (p110a) [46, 47], and PIK3CD (p110d) is also overexpressed in some gliomas [48]. Other amplified regions containing oncogenes, for example AKT3 [22, 49] and CCND2 [22, 27].

Over-expression of c-Myc is frequently observed in different tumor types, including glioblastoma, and usually results from chromosome translocation involving the c-Myc genes 
in addition to gene amplification [50]. In a study it was reported that during multistep carcinogenesis using fibroblast lineages transfected with SV40 LT, expression levels of cMyc and Sp1 associate with the levels of telomerase activity in different stages of transformation [51]. Transcriptional regulation of hTERT is thought to be the chief mechanism of telomerase regulation. Cooperative action of c-Myc and Sp1 is required for full activation of hTERT promoter. Sp1 is also a key molecule that binds to GC-rich sites on the core promoter and activates hTERT transcription [51]. In the core promoter, multiple Eboxes and Sp1 binding sites are located. C-Myc binds to these E-boxes through heterodimer formation with Max proteins and activates transcription of hTERT [52, 53]. This is a direct effect of c-myc that does not require de novo protein synthesis. Mad proteins are antagonists of c-Myc and switching from Myc/Max binding to Mad/Max binding decreases promoter activity of hTERT [51, 54-56]. Thus, up-regulation of these critical transcription factors may, at least in part, be involved in telomerase activation during carcinogenesis [57].

\begin{tabular}{|ccc|}
\hline Amplified Region & Gene of Interest & References \\
\hline $\mathbf{1 q}$ & AKT3 & {$[22,49]$} \\
\hline $\mathbf{q} \mathbf{q}$ & PIK3CA & {$[22,23,27]$} \\
\hline $\mathbf{4 q}$ & PDGFR & {$[22,34]$} \\
\hline $\mathbf{p} \mathbf{p}$ & EGFR, MET, HGF, CDK6 & {$[22,23,27,34,35]$} \\
\hline $\mathbf{8 q}$ & c-MYC & {$[50]$} \\
\hline $\mathbf{1 2 q}$ & CDK4, MDM2 & {$[22,27,35]$} \\
\hline
\end{tabular}

Table 1. Genes frequently identified to be amplified in glioblastoma

\subsection{Deletions}

Loss of heterozygosity $\mathrm{LOH}$ of chromosome $10 \mathrm{q}$ is the most common genomic alteration found in both primary and secondary glioblastomas $[28,35]$ and is associated with poor prognosis [26, 28]. Different regions are frequently lost at chromosome 10, including the regions containing PTEN, MGMT [28, 58], and ANXA7, an EGFR inhibitor [59]. PTEN directly antagonizes PI3K signaling and is one of the most frequently altered genes in cancer. It undergoes genomic loss, mutation, or epigenetic inactivation in $40 \%-50 \%$ of gliomas, resulting in high levels of PI3K activity and downstream signaling [60]. In addition, AKT activation due to PTEN loss likely contributes to RTK inhibitor insensitivity in glioblastoma [29, 61]. Another frequently deleted inhibitor of EGFR signaling is NFKBIA, which is located on chromosome 14; this deletion is also linked to poor survival [62]. Furthermore, loss of chromosome 9p, which contains a variety of tumor-suppressor genes, including CDKN2A, CDKN2B, and PTPRD, is frequently seen [28, 34, 63], especially in short-term survivors [26, 32]. CDKN2A and CDKN2B encode three important cell cycle proteins, p14ARF and p16INK4A, and p15INK4B [26-28, 34, 64], which are involved in the RB and P53 pathways. Deletion of CDKN2A and CDKN2B is often accompanied by deletion of CDKN2C on chromosome 1p32, which encodes another cell cycle protein p18INK4C [64]. $\mathrm{LOH}$ of chromosome $1 \mathrm{p}$ is found in both primary and secondary glioblastomas [65]. Longstanding hypothesis about the location of tumor suppressor gene at $1 p$ has recently 
been advanced by identification of the suggested candidate genes CIC and FUPB1 [66]. Codeletion of $1 \mathrm{p}$ and $19 \mathrm{q}$ is frequently seen in oligodendrogliomas and is, in those, associated with prolonged survival [32] and translocations [67]. Although this co-deletion has been observed in glioblastomas, no similar association has been identified elsewhere. Isolated $\mathrm{LOH} 19 \mathrm{q}$ is frequently observed in secondary glioblastoma $[26,65]$ and may be a marker of longer survival [26]. Moreover $>50 \%$ of oligodendrogliomas has been reported to display loss of heterozygosity $(\mathrm{LOH})$ at chromosomes $1 p$ and 19q [68], although the targets of these deletions are still unclear.

Frequent allelic losses on $22 \mathrm{q}$ indicating the presence of tumor suppressor genes have been found in primary and secondary glioblastomas [69]. $\mathrm{LOH}$ of $22 \mathrm{q}$ identified two sites of minimally deleted regions at 22q12.3-13.2 and 22q13.31 in primary glioblastomas and in most of the secondary glioblastomas. The affected shared deletion of $22 \mathrm{q} 12.3$ is the region in which the human tissue inhibitor of metalloproteinases-3 (TIMP-3) is located. As its name implies, expression of TIMP-3 inhibits metalloprotease activity and impair glioblastoma migration and invasiveness [70]. Expectedly, deletion of TIMP-3 enhances glioblastoma invasiveness [69].

It is important to note that the various deletions and amplifications do not exist in isolation. For instance, NFKBIA deletions and EGFR amplifications are essentially mutually exclusive events, suggesting that these events serve redundant functions in glioblastoma pathogenesis [62]. Systematic analysis of the patterns of co-occurrence of the various deletions and amplifications revealed genomic regions with synergistic tumor-promoting relationships [71]. Analysis of the general patterns of co-occurring and mutually exclusive regions in glioblastomas suggests common pathways that are disrupted during carcinogenesis. Targeting these pathways in the context of the genetic landscape of the glioblastoma constitutes one therapeutic strategy.

\begin{tabular}{|ccc|}
\hline Deleted Region & Gene of Interest & References \\
\hline $\mathbf{9} \mathbf{p}$ & CDKN2A, 2B & {$[22,27,35]$} \\
\hline $\mathbf{1 0} \mathbf{q}$ & PTEN, MGMT, ANXA7 & {$[22,23,34,35]$} \\
\hline $\mathbf{1 3} \mathbf{q}$ & RB & {$[22,34]$} \\
\hline $\mathbf{1 7} \mathbf{p}$ & P53, NF1 & {$[22,23,34]$} \\
\hline $\mathbf{1 9} \mathbf{q}$ & BAX & {$[34,65]$} \\
\hline $\mathbf{2} \mathbf{q}$ & TIMP3 & {$[69]$} \\
\hline
\end{tabular}

Table 2. Genes frequently identified to be deleted in glioblastoma

\section{Mutations}

The abnormal behaviors demonstrated by cancer cells are thought to be the result of a series of mutations in key regulatory genes. A detailed understanding of the genomic lesions underlying cancer will facilitate the identification of the cellular pathways and networks perturbed by genomic mutations, improve cancer diagnosis through molecular classification, enhance the selection of therapeutic targets for drug development, promote 
the development of faster and more efficient clinical trials using agents targeted to specific genomic abnormalities, and create markers for early detection and prevention. Results from the genomic profiling efforts and a number of studies over the past three decades have revealed that nearly all glioblastomas harbor activating mutations in genes that play instrumental role in growth signaling cascades, evading apoptosis, insensitivity to antigrowth signals. In addition to amplifications and deletions, genes implicated in glioblastoma can be affected by somatic mutations. Point mutations include base substitutions, deletions, or insertions in coding regions and splice sites. Large-scale mutation analysis has identified mutations activating oncogenes and others inactivating tumorsuppressor genes in glioblastoma.

It was previously thought that glioblastoma arises from the acquisition of a defined set of mutations that occur in a particular temporal order. This model is largely grounded on the framework established in colon cancer, where a series of genetic alterations characterizes different phases of neoplastic progression [72]. This hypothesis is supported by the observation that Grade II astrocytomas typically harbor mutations in p53; Grade III astrocytomas harbor activating mutations/amplifications of CDKN2A (p16Ink4a); and Grade IV astrocytomas harbor mutations in PTEN and EGFR [73]. This data was interpreted to suggest that glioblastoma results from sequential inactivation of the p53, RB, and RTK/PI3K axes. While such a paradigm may hold true for a subset of the secondary glioblastomas, the picture emerging from the genomic characterization of primary glioblastomas reveals a much more dynamic process [22, 23]. The profile of somatic mutations in different glioblastomas is highly variable. These results suggest that most glioblastomas, primary or secondary, evolve along a multitude of pathways in response to differing selective pressures to achieve the phenotypes described by Hanahan and Weinberg [74].

Aberrant centrosome behavior, such as centrosome amplification, has been associated with mutation of TP53 and has been proposed as a primary source of genetic instability in human tumors. Mutations in "common" cancer genes, for example TP53 and PTEN, are very frequent in glioblastomas, but are not of prognostic importance [22, 23, 28, 32, 33, 75]. On the other hand PTEN loss has been shown clinically to confer resistance to EGFR inhibitors in patients harboring EGFRvIII expressing glioblastoma in part due to its activation of downstream AKT [29, 76] as well as loss of its RTK degradation function [76].

There are several lines of evidence that point to the importance of the p53 axis in glioblastoma pathogenesis. There is a body of literature associating p53 pathway inactivation to glioblastoma genesis [37, 77]. It must be noted that these studies implicate p53 pathway inactivation only in a subset of glioblastomas. The TCGA effort and the effort by Parsons et al. $[22,23]$ enhanced the literature by demonstrating that the p53 axis is more broadly impaired in glioblastomas than previously thought. Mutations that inactivate this axis are found in greater than $70 \%$ of all glioblastoma specimens as reported by both studies. This understanding has led to more accurate modeling of glioblastoma by combined inactivation of p53 and PTEN [78]. 
There are a number of mutations that are thought be glioblastoma specific, even though they may be seen in only a subgroup of tumor cells. The EGFRvIII mutant lacks 267 amino acids in the extracellular part, resulting in a constitutively activated receptor that no longer requires its ligand EGF to signal downstream [79]. Despite the well-recognized proproliferative functions of EGFRvIII, its expression in human glioblastoma is heterogeneous and is most often observed only in a subpopulation of cells [80]. Recent observations support a model of functional heterogeneity in which a minority of EGFRvIIIexpressing cells not only drive their own intrinsic growth, but also potentiate the proliferation of adjacent wild-type EGFR-expressing cells in a paracrine fashion through the cytokine co-receptor gp130 [81]. EGFRvIII expression may be linked to differentiation and/ or development. EGFR point mutations have also been identified in glioblastoma, in the extracellular domain, whereas they are predominantly found in the kinase domain in other tumor types, such as lung cancer [82]. EGFR mutations have recently been identified as clinically significant, due to their association with striking responses in subsets of patients treated with targeted therapeutic agents. [83, 84].

The PI3K signaling pathway is dysregulated in many cancers [85], including glioblastomas. A number of investigations have reported activating mutations in the RTK-PI3K pathway $[43,86]$, validating the importance of this pathway in glioblastoma pathogenesis. Mutations in PIK3CA and PIK3R1, coding for the PI3K catalytic subunit p110a and regulatory subunit P85a, have been described [22, 23]. RTK-independent activation of this pathway in glioblastoma can occur via mutation of PIK3CA (p110a) [46, 47] or through recurrent mutations in the gene encoding the p85a regulatory subunit PIK3R1. This will likely drive PIK3CA activation through decreased SH2 domain-mediated inhibition [87]. In the TCGA report [22] activating mutations in the RTK-PI3K pathways are reported in $88 \%$ of the 206 glioblastomas sequenced.

Although mutations in the RAS genes constitute a fairly rare phenomenon in glioblastoma $(>5 \%)$ [88], inactivating mutations and deletions have been identified in their inhibitory tumor suppressor gene NF1 [22]. The protein encoded by neurofibromatosis 1 (NF1) functions to catalyze the exchange of GTP for GDP in Ras - preventing cell proliferation. While it is reported that NF1 patients are predisposed to gliomagenesis [89], inactivating mutations in NF1 was not discovered in glioblastoma until recently [22, 23, 90, 91]. The TCGA results indicated that approximately $20 \%$ of glioblastomas harbor loss of function mutations in NF1 $[22,23]$ and more significantly, mutations in NF1 appear to define a particular subtype of glioblastoma.

The majority of malignant brain tumors, including glioblastoma, demonstrate inactivating mutations in either the p53 and/or retinoblastoma (RB) pathways [92-95]. In addition to their adverse cellular functions, these two pathways are most directly involved in cell cycling regulations during times of cell repair or cell growth.

The TP53 tumor suppressor gene, located on 17p13, is frequently mutated or deleted in gliomas [96, 97]. P53 is a short-lived transcription factor that can execute diverse cellular programs, such as cell cycle arrest, DNA repair, apoptosis, autophagy, differentiation, 
senescence and self- renewal $[98,99]$. It facilitates DNA repair by halting the cell cycle for repair enzymes to work, or if the damage is too great, it induces cell death. The retinoblastoma $(\mathrm{Rb}, 13 \mathrm{q} 14)$ pathway is also a key cell cycle regulatory complex at the G1 checkpoint. CDKN2A, located on 9p21 and deleted in many cancers, encodes the p16 protein, a key inhibitor of the cell cycle via $\mathrm{Rb}$ pathway signaling. Homozygous deletion of p16 has been reported to be associated with WHO grade III or IV gliomas [7, 100]. Gliomas often display mutations in the ARF- MDM2-p53 and p16INK4A-CDK4-RB tumor suppressor pathways [101, 102]. Primary glioblastoma often exhibits loss of the INK4A/ARF tumor suppressor gene locus along with PTEN mutation and EGFR amplification/mutation, and secondary glioblastoma shows frequent mutations of TP53 [58].

The relevance of p53 to the treatment and outcome of patients with high-grade glioma has remained controversial. Some studies have shown that p53 status, assayed either by expression or mutation analysis, is correlated with relatively good outcome [103, 104], while others have demonstrated no prognostic impact in anaplastic gliomas and GBM $[105,106]$. Also, MDM2 amplification, although infrequent, has been shown by some to be predictive of poor outcome [103, 107], whereas others have observed no prognostic value [108]. P53 status might cooperate with other prognostic variables; for example, TP53 mutation has been linked to low MGMT mRNA expression [109], although this does not correlate with MGMT promoter methylation [110]. Loss of CDKN2A, CDKN2B, or RB or CDK4 amplification, disrupting the $\mathrm{Rb}$ pathway, has been shown in anaplastic astrocytoma to associate with decreased survival [111, 112]. Conversely, p16 appears to be associated with improved survival in patients treated with chemotherapy and radiation [113]. Overall, it appears that the prognostic impact of p53 and $\mathrm{Rb}$ aberrations is at best marginal.

Comprehensive analysis of genomic data in glioblastoma revealed recurrent mutations in the R132 residue of isocitrate dehydrogenase 1 (IDH1) and is involved in energy metabolism [23]. IDH1/2 is mutated in grade II and III gliomas as well as the secondary glioblastomas that arise from prior low-grade tumors, with most mutations found in the IDH1 gene. IDH1 mutations have been predominantly identified in secondary glioblastomas and low-grade gliomas, with mutations in more than $70 \%$ of cases [23, 114-118]. Patients with IDH1 mutated primary glioblastomas are generally younger and have longer median survival and wild-type EGFR. Because these are characteristics of secondary glioblastomas, it is hypothesized that these are in fact secondary glioblastomas for which no histological evidence of evolution from a less malignant glioma is found. Significantly, these mutations usually occur at conserved residues and are virtually never homozygous. While only $3 \%-7 \%$ of primary glioblastomas harbor IDH1 mutations, the majority $(50 \%-80 \%)$ of secondary glioblastomas express mutant IDH1. Thus, IDH1 could be used to differentiate primary from secondary glioblastomas [116]. In addition, 3\% of the tumors that express wild-type IDH1 were found to express IDH2 R172 mutations [117-120], although this mutation in IDH2 has only been documented in a single glioblastoma in the literature [121].

Studies on the downstream biological effects of IDH1/2 mutation expression have focused largely on the inhibition of $\alpha$-KG-dependent dioxygenases by $2-\mathrm{HG}$, as IDH mutations result in a novel function to catalyze $\alpha$-ketoglutarate $(\alpha-K G)$ to 2-hydroxyglutarate $(2-\mathrm{HG})$ 
[122]. The wild-type IDH1 normally functions as a homodimer that converts isocitrate to $\alpha$ ketoglutarate [120]. Biochemical depiction of the R132 mutated IDH1 revealed that it functions to inhibit the process. Thus, glioblastoma harboring the R132 IDH1 mutation harbor decreased levels of $\alpha$-KG. It is imperative to note that $\alpha-K G$ dependent dioxygenases is a diverse group of enzymes controls a broad range of physiological processes, including hypoxic sensing, histone demethylation, demethylation of hypermethylated DNA, fatty acid metabolism, and collagen modification, among others [123]. Several studies have provided evidence to demonstrate that several of these functions are influenced by IDH1/2 mutation expression.

Mutational and epigenetic profiling of patients specimen has revealed that IDH1 mutations closely associated with a specific hyper-methylation signature. The hyper-methylation state may be caused in part by the 2-HG-mediated inhibition of the $\alpha$-KG-dependent TET2 enzyme [124, 125]; the resultant decrease in 5-hydroxymethylcytosine was also observed in glioblastoma specimens [124]. Moreover, expression of IDH1 mutations is thought to induce global DNA hyper-methylation [126]. Thus it is suggested that IDH1 mutations may lead to dysregulated epigenetic processes. 2-HG inhibits histone demethylases and TET 5methylcytosine hydroxylases, thought to be involved in epigenetic control. This suggests that mutations in IDH1 change the expression of a potentially large number of genes [124].

Most lower-grade gliomas harbor IDH1 mutations; although grade I pilocytic astrocytomas usually express wild-type IDH1; $60 \%-80 \%$ of grade II and III astrocytomas, oligodendrogliomas, and oligoastrocytomas express mutant IDH1, with the R132H mutation representing the majority of mutations observed. Given that mutations in IDH1 are an early event in gliomagenesis [127], this may suggest widespread modification of epigenetic regulator as the key mechanism in gliomagenesis in IDH1 mutated tumors. Furthermore, it might explain the extensive and fundamental differences between mutated and wild-type IDH1 glioblastoma. It has been reported that global expression profiles of IDH1 mutant glioblastomas more closely resembled lineage-committed neural precursors, whereas wildtype counterparts appear to resemble neural stem cells [128].

Independent glioblastoma studies have pointed to IDH1 mutations as an objective positive prognostic marker [23, 114, 115, 120]. Reports of the association between IDH1 mutations and favorable prognosis hold promise for biomarker development [23, 42, 120], although these correlations await validation in prospective clinical trials. Thorough understanding of mutant IDH biology and the mutant status of the IDH1/2 genes may serve as a key prognostic indicator. Specifically, patients with anaplastic astrocytoma [23, 115, 120, 121] and glioblastoma harboring mutant IDH1 demonstrate a significantly longer overall survival compared with wild-type IDH1 counterparts and are younger at presentation. Similar survival benefit has also been observed in grade II gliomas. [115] Furthermore, a comprehensive genomic and clinical analysis of glioblastomas harboring mutant and wildtype IDH1 suggests that, while histo-pathologically similar, these tumors may represent disease processes far more unique than has been appreciated. Specifically, IDH1 mutant tumors display less contrast enhancement, less peritumoral edema, larger initial size, greater cystic components, and a greater likelihood of frontal lobe involvement compared with wild-type tumors [128]. 
A frequently encountered critique of genomic sequencing effort involves the following. The first generation sequencing used to characterize the glioblastoma landscape captures the most prevalent mutations. They did not analyze the deeper heterogeneity of low prevalence mutations that have been found in several tumor types, including colon cancer [129]. Efforts to examine whether such sub-clonal diversity exist in glioblastoms using highly sensitive techniques [130] have not identified the presence of low-prevalence mutations. These results suggest that clonal expansion of select mutation in glioblastoma constitute a major mechanism of tumor expansion and that random mutagenesis through mutator phenotype does not contribute significantly to glioblastoma pathogenesis. The insights gained from the TCGA and other sequencing efforts should be viewed in this light.

\section{Non-coding DNA sequences}

While the identification of nucleotide alterations within the coding sequence of protooncogenes or tumor suppressor genes has significantly contributed to our understanding of carcinogenesis, there is an emerging appreciation that alterations in noncoding sequences similarly contribute to development of cancer [131]. Non-coding DNA describes components of DNA arrangements that do not participate in the coding of protein sequences. These DNA sequences may present in different forms including non-coding functional RNA, cis- and trans-regulatory elements, introns, pseudogenes, repeat sequences, transposons, and telomeres. A notable example involves the regulation of gene transcription by reversible modification of gene promoter regions a phenomenon often referred to as 'epigenetic regulation' [132]. The term 'epigenetic regulation' describes the phenomenon in which heritable changes in gene expression can occur in the absence of changes in the DNA sequences encoding for gene function. Understanding the concept that non-coding sequences play critical roles in glioblastoma pathogenesis and resistance to chemotherapy offers novel strategies for biomarker development and therapy.

The mechanism underlying epigenetic involves cytosine methylation [133] or histone modifications that, in turn, modulate the accessibility of gene promoter regions to transcriptional factors [134]. Cytosine methylation often occurs in the context of CpG dinucleotide repeats, or $\mathrm{CpG}$ islands [133]. Thus promoters that harbor heavily methylated CpG islands are typically transcriptionally silenced. There are two types of promoter methylation that are particularly pertinent to glioblastoma therapy: methylation in the promoter region of the DNA repair gene, methyl-guanine methyl transferase (MGMT) and the glioma-CpG island methylator (G-CIMP) phenotype [135].

MGMT encodes an enzyme that removes alkyl adducts at the O6 position of guanine [136]. Because alkyl modification at this position is highly toxic and constitutes the primary mechanism for the tumoricidal activity of the chemotherapeutic agent TMZ, MGMT expression level correlates well with TMZ response in patients with glioblastoma [137]. The human MGMT gene possesses a CpG island that spans approximately 1000 bases around the transcriptional start site. Detailed analysis of this region revealed 108 CpG sites [138] that are methylated. Methylation of a subset of these CpGs has been associated with 
transcriptional silencing of MGMT [139, 140] and is associated with improved clinical outcome in patients with glioblastoma receiving TMZ therapy. Interestingly, MGMT promoter methylation is also associated with improved survival in patients who did not receive TMZ therapy [141, 142]. While the mechanism underlying this observation remains unclear, it seems likely that MGMT may participate in detoxifying the accumulation of endogenous DNA damage that is typically associated with the oncogenic state [143]. Glioblastoma cells accumulate endogenous DNA damage in the absence of DNA damaging agents [143]. These endogenous DNA damages are not unlike those induce by temozolomide or radiation in that they could trigger cell death if unrepaired. Thus, tumors with high levels of MGMT may grow more robustly since MGMT is capable of detoxifying these endogenous DNA damages. If the tumor cells grow more robustly, the patient will survive for a shorter duration. In contrast, the glioblastoma cells with low MGMT may be more susceptible to the deleterious effects of the endogenous DNA damages. These tumors may grow less robustly, resulting in longer patient survival.

The G-CIMP phenotype refers to the observation that a subset of glioblastomas exhibits concerted CpG island methylation at a large number of loci [144]. Since genes required for tumour growth are located at many of these loci, glioblastomas harboring the G-CIMP phenotype tend to be more benign. Correspondingly, patients with G-CIMP glioblastomas experienced significantly improved outcome. Understanding the concept that the patterns of CpG island methylation directly impact outcomes in patients with glioblastoma open the door to therapeutic strategies aimed at enhancing promoter methylation at select promoter loci. Importantly, recent studies suggest that promoter methylation at distinct loci may be affected by specific chromatin-modulating factors [135, 145].

While much of cellular DNA has no known biological function, many types of non-coding DNA sequences do have recognized biological functions, including the transcriptional and translational regulation of protein-coding sequences. These governing functions may include genetic switches, regulation of gene expression, transcription factors, operators, enhancers, promoters, and insulators [146-148]. Genome-wide association (GWA's) studies have uncovered a large number of cancer susceptibility regions that do not overlap proteincoding genes but rather map to non-coding intervals [132, 135]. The concept that non-coding DNA sequences regulate gene function and impact carcinogenesis has significantly expanded the repertoire of strategies available for glioblastoma therapeutics [135]. Integrating the biology of non-coding sequences in the context of mutational profile is critical in understanding tumor physiology and meaningful therapeutic development.

\section{Over-expressed mRNA}

Over-expression or under-expression of genes in glioblastoma compared with that in a normal brain or in low-grade gliomas may serve as an indication of genes that are involved in gliomagenesis [24]. While glioblastoma has been conceptualized as a single disease, it is widely appreciated that the term captures significant histologic heterogeneity. This heterogeneity suggests distinct subtypes with differing physiologic states that are captured 
under the umbrella term "glioblastoma" [21]. In fact, the genome-wide analysis of mRNA expression to identify molecular subclasses (Golub et al. 1999) has led to a fundamental shift in our understanding of glioblastoma subtypes. In fact, the identification of multiple subtypes within glioblastoma has highlighted the heterogeneity of diseases that are in the same group based on the WHO histo-pathological grade.

Primary and secondary glioblastoma subtypes are histo-pathologically indistinguishable, but differences can be demonstrated by molecular markers at the epigenetic [69], genetic [28, 35, 58], expression [149], and proteomic [150] levels. Primary glioblastomas have a greater prevalence of EGFR alterations, MDM2 duplications, PTEN mutations, and homozygous deletions of CDKN2A [28, 58]. MET amplification [35], over-expression of PDGFRA, and mutations in IDH1 and TP53 are more prevalent in secondary glioblastomas [23, 29, 58, 75, $114,116,118]$. Moreover, the large-scale analysis has revealed the highly structured nature of glioma transcriptome and has shown correlation of tumor histology and molecular alterations with patient outcome [10, 24, 42]. While expression profiling of glioblastoma has been widely used, two fundamental studies have provided the groundwork for the classification of glioblastoma subtypes [30,42]. The first subtype initially reported by Phillips et al. [30] and subsequently confirmed by the TCGA mRNA [42] and microRNA profiling [151]. The transcript signature resembles those of neuro-blasts and oligodendrocytes derived from fetal and adult brain cells [30]. The subtype harbors transcriptomal and clinical features that emulate those previously classified as secondary glioblastomas. Molecularly, proneural glioblastomas harbor mutations classically associated with the secondary glioblastomas [42]. Hence, grade II and III gliomas harbor transcriptomal signatures most reminiscent of the proneural subtype [30]. Clinically, this subtype typically affects younger patients, is associated with improved overall survival [30], and responds poorly to concurrent radiation/temozolomide treatment upon disease progression [42].

The second subtype that has emerged is characterized by a gene expression signature that illustrates those observed in the neural stem cells of the forebrain [30], cultured astroglial cells [152], and tissue of mesenchymal origin [30]. Thus, the subtype is termed "mesenchymal" for the latter correlation. Similar to the proneural subtype, this second subtype was initially identified by Phillips et al. [30] and subsequently confirmed by the TCGA [42]. This subtype is highly enriched for mutations inactivating NF1, suggesting a common genetic etiology. The mesenchymal signature appear driven a common transcriptional network, as expression of two key critical factors (STAT3 and CEBPb) enhance tumor aggressiveness in murine models [153].

Benefiting from unsupervised hierarchical clustering analysis, Verhaak et al. (2010) classified 200 TCGA glioblastoma samples into four subtypes, which were subsequently validated using previously published data from 260 independent samples. Large-scale expression studies are validated by reverse transcription (RT)-PCR for individual genes. Bioinformatics analysis revealed that three of the four subtypes were found to harbor distinct molecular aberrations. In particular, the proneural subtype was enriched for amplifications of PDGFRA, CDK6, CDK4, and MET; 11 out of 12 IDH1 mutations found in 
the TCGA samples; PIK3CA/ PIK3R1mutations; and mutation or LOH of TP53. While the mesenchymal subtype carries mutations and/or loss of NF1, TP53, and CDKN2A, the classical subtype shows amplification for EGFR and loss of PTEN. On the other hand, to date no distinguishing genetic alterations have been indicated to define the neural class from the other classes [20]. It is imperative to keep in mind that interpretations of these results are difficult due to methodological differences in profiling platforms, bioinformatic extrapolation, and specimen collection.

While the number of subtypes identified by the Verhaak et al. (2010) and Phillips et al. (2006) studies differs, the proneural and mesenchymal classifications identified using distinct methodologies and sample sets are the most robust and concordant [10]. For instance, both groups identified proneural class expression of DLL3 and OLIG2 and mesenchymal class expression of CD40 and CHI3L1/YKL-40, the latter of which appears to be a potential serum protein marker of prognosis in glioblastoma patients [154]. Both studies share the observation that patients afflicted with the mesenchymal subtype exhibit poorer clinical prognosis relative to the proneural subtype. A high level of expression of insulin-like growth factor binding proteins, for example IGFBP-2/3 [155], angiogenesic factors, such as vascular endothelial growth factor A (VEGFA) [156], and mesenchymal markers, like YKL40/CHI3L1, are frequently seen in glioblastoma and have been associated with poor prognosis [157-159]. In contrast, NOTCH signaling genes, for example DLL3, are indicative of better survival [160].

Hence, the collection of data suggests at least two distinct subtypes that reflect essential biologic behavior [10, 30, 42] and have been validated by independent studies. In addition to promising improvement in the grading of glioblastoma, gene expression profiling has shown great promise in prognosis of this deadly tumor, as the genes represented in these subtypes could help to predict outcome in glioblastoma. For example, increased expression of mesenchymal genes such as CHI3L1/YKL-40 and LGALS3 combined with decreased expression of a proneural gene, OLIG2, are associated with typical short-termsurvival compared with longer-termsurvivors [161]. Additional studies have extended the utility of mRNA profiling by using computational network analysis to uncover the causal regulatory modules underlying particular transcriptomically defined subtypes. It is important to note that most of these subtypes have not been as rigorously validated as the proneural and the mesenchymal. The emerging literature suggests that the proneural and mesenchymal subtypes define the two poles in the spectrum of molecular glioblastoma physiology [10, 30, 42]. It remains unclear whether the other proposed subtypes constitute a "forced fit" of a set of truly heterogeneous biology, a gradation of phenotypes between the two extreme poles, or a genuine subtype whose biologic basis remains to be understood.

With genomics approaches, discoveries of common features of different types of tumor may lead to new therapeutic targets and drugs for other tumor types also. The discovery of overexpression of VEGFA and its correlation with poor prognosis in glioblastomas [156] led to trials with the angiogenesis inhibitor bevacizumab. 


\section{Micro-RNA (miRNA) dysregulation}

Micro-RNAs (miRNA or miR) are a class of small non-coding RNAs, approximately 22 nucleotides long that are involved in post-transcriptional gene regulation [162]. Through imperfect pairing, miRNA's bind to untranslated regions of protein-coding mRNAs and function mainly as negative regulators of gene expression. Binding of miRNA often leads to mRNA degredation or inhibition of protein translation - resulting in suppression of the target proteins. A number of cellular processes are regulated by miRNAs including development, proliferation, and differentiation. Micro-RNAs play an important role in many different disorders, particularly in cancer [163]. Bioinformatic analysis predicts that a single miRNA can potentially regulate hundreds of target oncogenes or tumour suppressor proteins. The association of miRNA deregulation with pathogenesis and progression of malignant disease illustrates great potential of utilizing miRNAs as targets for therapeutic intervention. Thus, modulation of miRNA expression provides great hope for potential cancer therapy. Furthermore, since each miRNA may have more than one target, miRNAbased gene therapy offers the therapeutic appeal of targeting multiple gene networks that are controlled by a single miRNA [164]. Over 1000 miRNAs have been described in humans [165]. Bioinformatics analysis has recently revealed that miRNAs are differentially expressed in glioblastoma tissues compared to normal brain tissue [166-169]. For example, while primary glioblastomas and cell lines over-express miR-221 and miR-222, which are thought to target cell cyclin-dependent kinase inhibitors p27 and p57, set of brain-enriched miRNAs (miR-128, miR-181a, miR-181b, and miR-181c) show reduced expression [170, 171].

\section{miRNA}

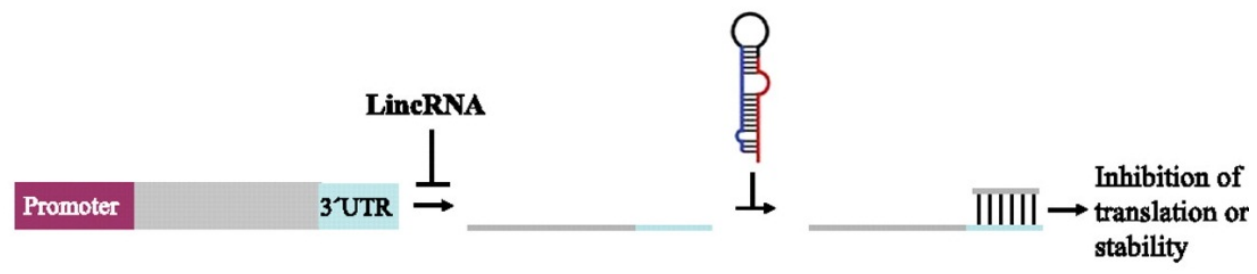

\section{Methylation}

||І||||||||

Promoter

\section{No transcripts}

Figure 1. Gene regulation by non-coding RNAs. Figure is adapted with permission from reference [135].

Frequently up-regulated miRNAs are called onco-miRNAs and are thought to contribute to carcinogenesis. As an example miRNA-10b is known to be highly expressed in glioblastoma samples [170], suggesting an important role for miR-10b in glioblastoma tumorigenesis. Furthermore, a recent study revealed that miR-10b expression is inversely correlated with glioblastoma patient survival [172]. Notably, miR-10b was also found to be up-regulated in breast cancer, leukemia, and pancreatic cancer and promote tumor invasion and metastasis in breast cancer [173-175]. These results suggest that some miRNAs, such as miR-10b, may function as a global oncogene to trigger tumorigenesis in multiple tissues. Another example 
of onco-miRNA in glioblastoma is miR-26a, which is thought to target PTEN [176]. PTEN has been reported to be down-regulated in $70 \%$ of human cancers, and there are several indications that it functions as a haplo-insufficient tumor suppressor gene [177]. PTEN expression is down-regulated by several different miRNAs, and it is thought that posttranscriptional regulation is an essential player in determining PTEN abundance in cancer cells. By targeting the tumor suppressor PTEN, overexpression of miR-26a facilitates tumorigenesis [168, 176]. Furthermore, miR-26 cooperates with oncogenes CDK4 and CENTG1, forming an onco-miRNA/oncogene cluster, targeting the RB, PI3K/AKT, and JNK pathways and increasing aggressiveness in glioblastoma [168]. Over-expressed oncogenic miRNAs may be targeted by antagomirs or miRNA sponges, because over-expression of the onco-miRNAs miR-26a, miR-196, and miR-451 has been correlated with poorer survival [167].

In contrast with the onco-miRNA's, frequently down-regulated miRNA's in glioblastoma are considered tumor-suppressor miRNA's. Reduced miR-128 expression in glioblastoma and consequent reduced cell proliferation in vitro and in xenografts [178]. Furthermore, miR128 regulates the expression of the complex protein Bmi-1 through binding at the BMI-1 3'UTR, resulting in decreased Bmi-1 and H3K27me3 levels. In GBM-derived neurosphere cells, miR-128 over-expression has been reported to block stem cell self-renewal, indicating that miR-128 can govern the stem cell-like capabilities of a subset of GBM cells [132]. Glioblastoma tumor tissue profiling has revealed that miRNA-124 is down-regulated in glioblastoma tissue $[163,170]$. Notably, miR-124 is also frequently down-regulated in other cancers, such as medulloblastoma, hepatocellular carcinoma, and oral squamous carcinoma $[179$, 180], suggesting that it may function as a general tumor suppressor. Moreover, miRNA-137 and miRNA-451 exhibit reduced expression in malignant glioblastoma tissues relative to normal brain tissues [181, 182].

Despite advances in biomedical science, the prognosis of glioblastoma patients remains poor. Biomarkers for this disease are needed for early detection of tumor progression. Clinical significance of miRNA expression profiles in glioblastoma has not been explored extensively. Nevertheless, 16 candidate miRNAs have been described to associate with malignant behavior of gliomas (miR-196a, miR-15b, miR-105, miR-367, miR-184, miR-196b, miR-363, miR-504, miR-302b, miR-128b, miR-601， miR-21，miR-517c，miR-302d, miR-383, miR-135b). Among them, miR-196a and miR-196b indicated the highest level of significance) [183]. Both miRNAs showed increased expression levels in glioblastomas relative to anaplastic astrocytomas and normal brain tissues. Higher level of miR-196 transcript significantly correlated with poorer survival [167, 183]. Treatment of malignant gliomas remains one of the greatest challenges facing oncologists today through a frequent resistance to both chemo- and radiotherapeutic agents [184]. Important question for management of glioblastoma patients is the possibility of predicting therapeutic outcome. The miRNA expression profiles of glioblastoma tissues have shown association of miR-181b and miR-181c with response to concomitant chemoradiotherapy with temozolomide (RT/RMZ). MiR-181b and miR-181c were significantly down-regulated in glioblastoma tissue of patients who responded to RT/TMZ in comparison to patients with progressive 
disease [183, 185]. In a recent study by Zhang et al. [186] genome-wide miRNA profiling of 82 glioblastomas demonstrated that miR-181d was inversely associated with patient overall survival and temozolomide (TMZ) treatment. Bioinformatics analysis of potential genes regulated by miR-181d revealed methyl-guanine-methyl-transferase (MGMT) as a downstream target. Together, these results suggest that miR-181d is a predictive biomarker for TMZ response and that its role is mediated, in part, by post-transcriptional regulation of MGMT.

The basic strategy of current miRNA-based treatment studies is either to antagonize the expression of target miRNAs with antisense technology or to restore or strengthen the function of given miRNAs to inhibit the expression of certain protein-coding gene. Unfortunately, several major challenges have to be addressed before the application of miRNA-based treatment. First, the multi-targeting nature of miRNAs gives the risk of unintended off-target effects that need to be carefully evaluated. Moreover, the expression of target gene may be governed by several different miRNAs, which may compromise the effect of miRNA-based treatment. Finally, there is still lack of miRNA delivery system with enough specificity and efficacy [183].

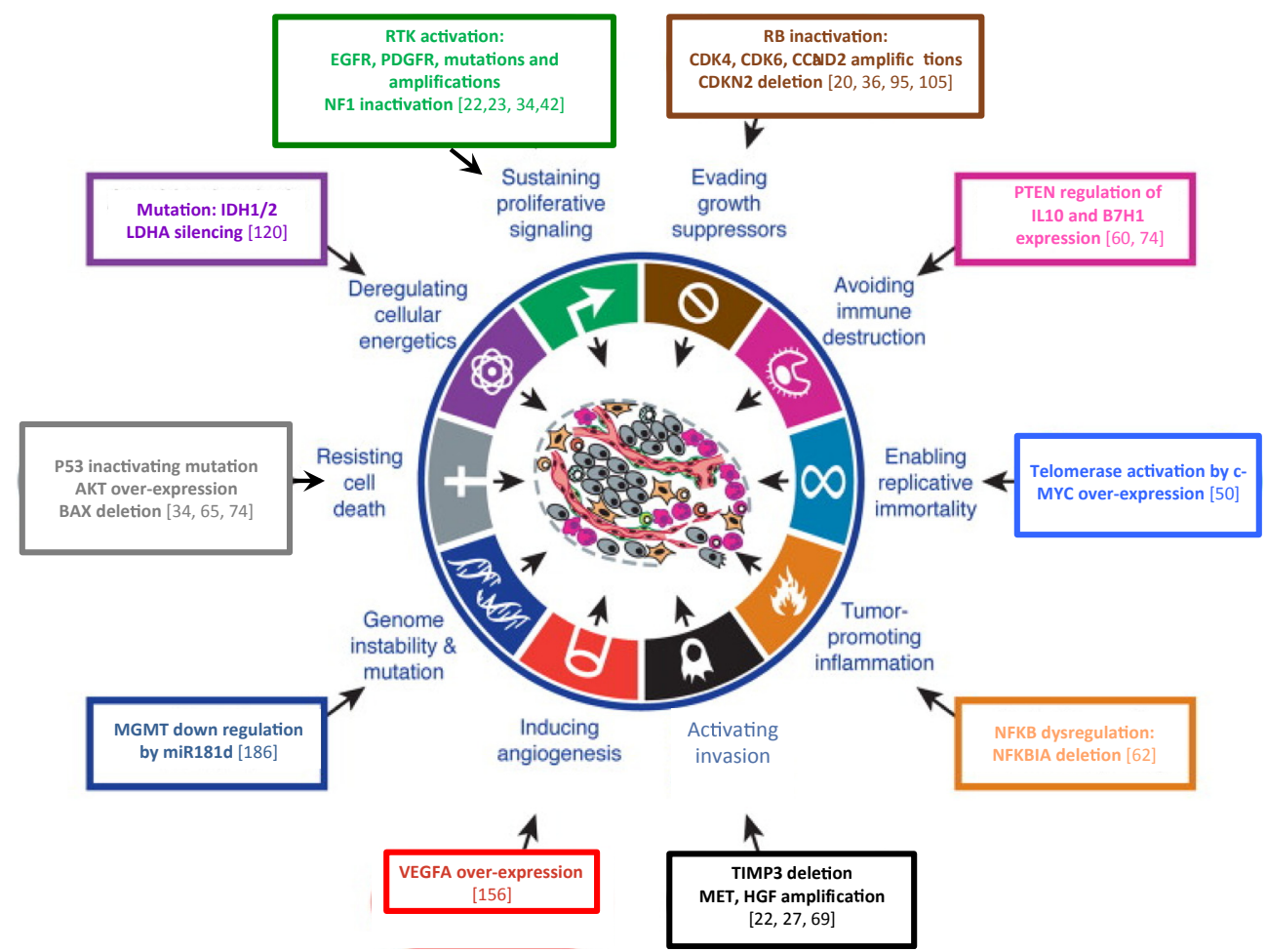

Figure 2. TCGA revealed genes that are known to contribute to the cancer phenotype, as proposed by Hanahan and Weinberg (2011). Figure is adapted with permission from reference [8]. 


\section{Conclusion}

In this chapter, we have reviewed and discussed key molecular participants glioblastoma, including chromosomal aberration, mutations, non-coding DNA sequences, over-expressed mRNA, and miRNA dysregulation. We placed our focus to explore the opportunities for major therapeutic developments in the cancer genomic era, where a more comprehensive mechanistic insight into glioblastoma pathogenesis and biology is arguably the most promising approach to discoveries of innovative treatment strategies.

Future development of tools for subtyping, biomarker development, and therapeutic strategies grounded in the genomic landscape of the particular glioblastoma will facilitate clinical trial designs. Ultimately, robust therapeutic gain can be achieved only when agents are directed toward the most vulnerable features inherent within the distinct physiologies of different glioblastoma.

\section{Author details}

Pouya Jamshidi

School of Medicine, University of California at San Diego, La Jolla, CA, USA

Center for Theoretical and Applied Neuro-Oncology, Moores Cancer Center,

Health Sciences Drive, La Jolla, CA, USA

Clark C. Chen

Center for Theoretical and Applied Neuro-Oncology, Moores Cancer Center, Health Sciences Drive, La Jolla, USA

Division of Neurosurgery, University of California, San Diego Health System, Health Science Drive, La Jolla, USA

\section{Acknowledgement}

This work was supported by the American Association of Neurological Surgeons (AANS) Medical Student Summer Research Fellowship (P.J.), Doris Duke Charitable Foundation Clinical Scientist Development Award (C.C.C.), the Sontag Foundation Distinguished Scientist Award (C.C.C.), the Burroughs Wellcome Fund Career Awards for Medical Sciences (C.C.C.), and an National Cancer Institute K12 award (C.C.C.).

\section{References}

[1] Wen PY, Kesari S. Malignant gliomas in adults. The New England journal of medicine. 2008;359(5):492-507. Epub 2008/08/02.

[2] Jemal A, Siegel R, Xu J, Ward E. Cancer statistics, 2010. CA: a cancer journal for clinicians. 2010;60(5):277-300. Epub 2010/07/09.

[3] Walker MD, Alexander E, Jr., Hunt WE, MacCarty CS, Mahaley MS, Jr., Mealey J, Jr., et al. Evaluation of BCNU and/or radiotherapy in the treatment of anaplastic gliomas. A cooperative clinical trial. Journal of neurosurgery. 1978;49(3):333-43. Epub 1978/09/01. 
[4] Stupp R, Mason WP, van den Bent MJ, Weller M, Fisher B, Taphoorn MJ, et al. Radiotherapy plus concomitant and adjuvant temozolomide for glioblastoma. The New England journal of medicine. 2005;352(10):987-96. Epub 2005/03/11.

[5] Alcantara Llaguno S, Chen J, Kwon CH, Jackson EL, Li Y, Burns DK, et al. Malignant astrocytomas originate from neural stem/progenitor cells in a somatic tumor suppressor mouse model. Cancer cell. 2009;15(1):45-56. Epub 2008/12/30.

[6] Ignatova TN, Kukekov VG, Laywell ED, Suslov ON, Vrionis FD, Steindler DA. Human cortical glial tumors contain neural stem-like cells expressing astroglial and neuronal markers in vitro. Glia. 2002;39(3):193-206. Epub 2002/08/31.

[7] Louis DN, Ohgaki H, Wiestler OD, Cavenee WK, Burger PC, Jouvet A, et al. The 2007 WHO classification of tumours of the central nervous system. Acta neuropathologica. 2007;114(2):97-109. Epub 2007/07/10.

[8] Hanahan D, Weinberg RA. Hallmarks of cancer: the next generation. Cell. 2011;144(5):646-74. Epub 2011/03/08.

[9] Stratton MR, Campbell PJ, Futreal PA. The cancer genome. Nature. 2009;458(7239):71924. Epub 2009/04/11.

[10] Huse JT, Phillips HS, Brennan CW. Molecular subclassification of diffuse gliomas: seeing order in the chaos. Glia. 2011;59(8):1190-9. Epub 2011/03/30.

[11] Hanahan D, Weinberg RA. The hallmarks of cancer. Cell. 2000;100(1):57-70. Epub 2000/01/27.

[12] Albertson DG, Collins C, McCormick F, Gray JW. Chromosome aberrations in solid tumors. Nature genetics. 2003;34(4):369-76. Epub 2003/08/19.

[13] Schrock E, du Manoir S, Veldman T, Schoell B, Wienberg J, Ferguson-Smith MA, et al. Multicolor spectral karyotyping of human chromosomes. Science. 1996;273(5274):494-7. Epub 1996/07/26.

[14] Speicher MR, Gwyn Ballard S, Ward DC. Karyotyping human chromosomes by combinatorial multi-fluor FISH. Nature genetics. 1996;12(4):368-75. Epub 1996/04/01.

[15] Kallioniemi A, Kallioniemi OP, Sudar D, Rutovitz D, Gray JW, Waldman F, et al. Comparative genomic hybridization for molecular cytogenetic analysis of solid tumors. Science. 1992;258(5083):818-21. Epub 1992/10/30.

[16] Pinkel D, Segraves R, Sudar D, Clark S, Poole I, Kowbel D, et al. High resolution analysis of DNA copy number variation using comparative genomic hybridization to microarrays. Nature genetics. 1998;20(2):207-11. Epub 1998/10/15.

[17] Knuutila S, Autio K, Aalto Y. Online access to CGH data of DNA sequence copy number changes. The American journal of pathology. 2000;157(2):689. Epub 2000/08/10.

[18] Hampton GM, Larson AA, Baergen RN, Sommers RL, Kern S, Cavenee WK. Simultaneous assessment of loss of heterozygosity at multiple microsatellite loci using semi-automated fluorescence-based detection: subregional mapping of chromosome 4 in cervical carcinoma. Proceedings of the National Academy of Sciences of the United States of America. 1996;93(13):6704-9. Epub 1996/06/25.

[19] Zhao X, Li C, Paez JG, Chin K, Janne PA, Chen TH, et al. An integrated view of copy number and allelic alterations in the cancer genome using single nucleotide polymorphism arrays. Cancer research. 2004;64(9):3060-71. Epub 2004/05/06. 
[20] Dunn GP, Rinne ML, Wykosky J, Genovese G, Quayle SN, Dunn IF, et al. Emerging insights into the molecular and cellular basis of glioblastoma. Genes \& development. 2012;26(8):756-84. Epub 2012/04/18.

[21] Ng K, Kim R, Kesari S, Carter B, Chen CC. Genomic profiling of glioblastoma: convergence of fundamental biologic tenets and novel insights. Journal of neurooncology. 2012;107(1):1-12. Epub 2011/10/18.

[22] Comprehensive genomic characterization defines human glioblastoma genes and core pathways. Nature. 2008;455(7216):1061-8. Epub 2008/09/06.

[23] Parsons DW, Jones S, Zhang X, Lin JC, Leary RJ, Angenendt P, et al. An integrated genomic analysis of human glioblastoma multiforme. Science. 2008;321(5897):1807-12. Epub 2008/09/06.

[24] Bleeker FE, Molenaar RJ, Leenstra S. Recent advances in the molecular understanding of glioblastoma. Journal of neuro-oncology. 2012;108(1):11-27. Epub 2012/01/25.

[25] Mulholland PJ, Fiegler H, Mazzanti C, Gorman P, Sasieni P, Adams J, et al. Genomic profiling identifies discrete deletions associated with translocations in glioblastoma multiforme. Cell Cycle. 2006;5(7):783-91. Epub 2006/04/04.

[26] Burton EC, Lamborn KR, Feuerstein BG, Prados M, Scott J, Forsyth P, et al. Genetic aberrations defined by comparative genomic hybridization distinguish long-term from typical survivors of glioblastoma. Cancer research. 2002;62(21):6205-10. Epub 2002/11/05.

[27] Beroukhim R, Getz G, Nghiemphu L, Barretina J, Hsueh T, Linhart D, et al. Assessing the significance of chromosomal aberrations in cancer: methodology and application to glioma. Proceedings of the National Academy of Sciences of the United States of America. 2007;104(50):20007-12. Epub 2007/12/14.

[28] Ohgaki H, Dessen P, Jourde B, Horstmann S, Nishikawa T, Di Patre PL, et al. Genetic pathways to glioblastoma: a population-based study. Cancer research. 2004;64(19):68929. Epub 2004/10/07.

[29] Mellinghoff IK, Wang MY, Vivanco I, Haas-Kogan DA, Zhu S, Dia EQ, et al. Molecular determinants of the response of glioblastomas to EGFR kinase inhibitors. The New England journal of medicine. 2005;353(19):2012-24. Epub 2005/11/12.

[30] Phillips HS, Kharbanda S, Chen R, Forrest WF, Soriano RH, Wu TD, et al. Molecular subclasses of high-grade glioma predict prognosis, delineate a pattern of disease progression, and resemble stages in neurogenesis. Cancer cell. 2006;9(3):157-73. Epub 2006/03/15.

[31] Lopez-Gines C, Gil-Benso R, Ferrer-Luna R, Benito R, Serna E, Gonzalez-Darder J, et al. New pattern of EGFR amplification in glioblastoma and the relationship of gene copy number with gene expression profile. Modern pathology : an official journal of the United States and Canadian Academy of Pathology, Inc. 2010;23(6):856-65. Epub 2010/03/23.

[32] Krex D, Klink B, Hartmann C, von Deimling A, Pietsch T, Simon M, et al. Long-term survival with glioblastoma multiforme. Brain : a journal of neurology. 2007;130(Pt 10):2596-606. Epub 2007/09/06.

[33] Weller M, Felsberg J, Hartmann C, Berger H, Steinbach JP, Schramm J, et al. Molecular predictors of progression-free and overall survival in patients with newly diagnosed 
glioblastoma: a prospective translational study of the German Glioma Network. Journal of clinical oncology : official journal of the American Society of Clinical Oncology. 2009;27(34):5743-50. Epub 2009/10/07.

[34] Yin D, Ogawa S, Kawamata N, Tunici P, Finocchiaro G, Eoli M, et al. High-resolution genomic copy number profiling of glioblastoma multiforme by single nucleotide polymorphism DNA microarray. Molecular cancer research : MCR. 2009;7(5):665-77. Epub 2009/05/14.

[35] Maher EA, Brennan C, Wen PY, Durso L, Ligon KL, Richardson A, et al. Marked genomic differences characterize primary and secondary glioblastoma subtypes and identify two distinct molecular and clinical secondary glioblastoma entities. Cancer research. 2006;66(23):11502-13. Epub 2006/11/23.

[36] Costello JF, Plass C, Arap W, Chapman VM, Held WA, Berger MS, et al. Cyclindependent kinase 6 (CDK6) amplification in human gliomas identified using twodimensional separation of genomic DNA. Cancer research. 1997;57(7):1250-4. Epub 1997/04/01.

[37] Henson JW, Schnitker BL, Correa KM, von Deimling A, Fassbender F, Xu HJ, et al. The retinoblastoma gene is involved in malignant progression of astrocytomas. Annals of neurology. 1994;36(5):714-21. Epub 1994/11/01.

[38] Shete S, Hosking FJ, Robertson LB, Dobbins SE, Sanson M, Malmer B, et al. Genomewide association study identifies five susceptibility loci for glioma. Nature genetics. 2009;41(8):899-904. Epub 2009/07/07.

[39] Wrensch M, Jenkins RB, Chang JS, Yeh RF, Xiao Y, Decker PA, et al. Variants in the CDKN2B and RTEL1 regions are associated with high-grade glioma susceptibility. Nature genetics. 2009;41(8):905-8. Epub 2009/07/07.

[40] Holtkamp N, Ziegenhagen N, Malzer E, Hartmann C, Giese A, von Deimling A. Characterization of the amplicon on chromosomal segment $4 \mathrm{q} 12$ in glioblastoma multiforme. Neuro-oncology. 2007;9(3):291-7. Epub 2007/05/17.

[41] Brennan C, Momota H, Hambardzumyan D, Ozawa T, Tandon A, Pedraza A, et al. Glioblastoma subclasses can be defined by activity among signal transduction pathways and associated genomic alterations. PloS one. 2009;4(11):e7752. Epub 2009/11/17.

[42] Verhaak RG, Hoadley KA, Purdom E, Wang V, Qi Y, Wilkerson MD, et al. Integrated genomic analysis identifies clinically relevant subtypes of glioblastoma characterized by abnormalities in PDGFRA, IDH1, EGFR, and NF1. Cancer cell. 2010;17(1):98-110. Epub 2010/02/05.

[43] Clarke ID, Dirks PB. A human brain tumor-derived PDGFR-alpha deletion mutant is transforming. Oncogene. 2003;22(5):722-33. Epub 2003/02/06.

[44] Ozawa T, Brennan CW, Wang L, Squatrito M, Sasayama T, Nakada M, et al. PDGFRA gene rearrangements are frequent genetic events in PDGFRA-amplified glioblastomas. Genes \& development. 2010;24(19):2205-18. Epub 2010/10/05.

[45] Wang H, Wang H, Zhang W, Huang HJ, Liao WS, Fuller GN. Analysis of the activation status of Akt, NFkappaB, and Stat3 in human diffuse gliomas. Laboratory investigation; a journal of technical methods and pathology. 2004;84(8):941-51. Epub 2004/06/09. 
[46] Gallia GL, Rand V, Siu IM, Eberhart CG, James CD, Marie SK, et al. PIK3CA gene mutations in pediatric and adult glioblastoma multiforme. Molecular cancer research : MCR. 2006;4(10):709-14. Epub 2006/10/20.

[47] Kita D, Yonekawa Y, Weller M, Ohgaki H. PIK3CA alterations in primary (de novo) and secondary glioblastomas. Acta neuropathologica. 2007;113(3):295-302. Epub 2007/01/20.

[48] Mizoguchi M, Nutt CL, Mohapatra G, Louis DN. Genetic alterations of phosphoinositide 3-kinase subunit genes in human glioblastomas. Brain Pathol. 2004;14(4):372-7. Epub 2004/12/21.

[49] Ichimura K, Vogazianou AP, Liu L, Pearson DM, Backlund LM, Plant K, et al. 1p36 is a preferential target of chromosome 1 deletions in astrocytic tumours and homozygously deleted in a subset of glioblastomas. Oncogene. 2008;27(14):2097-108. Epub 2007/10/16.

[50] Alitalo K, Koskinen P, Makela TP, Saksela K, Sistonen L, Winqvist R. myc oncogenes: activation and amplification. Biochimica et biophysica acta. 1987;907(1):1-32. Epub 1987/04/20.

[51] Kyo S, Takakura M, Taira T, Kanaya T, Itoh H, Yutsudo M, et al. Sp1 cooperates with cMyc to activate transcription of the human telomerase reverse transcriptase gene (hTERT). Nucleic acids research. 2000;28(3):669-77. Epub 2000/01/19.

[52] Wu KJ, Grandori C, Amacker M, Simon-Vermot N, Polack A, Lingner J, et al. Direct activation of TERT transcription by c-MYC. Nature genetics. 1999;21(2):220-4. Epub 1999/02/13.

[53] Greenberg RA, O'Hagan RC, Deng H, Xiao Q, Hann SR, Adams RR, et al. Telomerase reverse transcriptase gene is a direct target of c-Myc but is not functionally equivalent in cellular transformation. Oncogene. 1999;18(5):1219-26. Epub 1999/02/18.

[54] Gunes C, Lichtsteiner S, Vasserot AP, Englert C. Expression of the hTERT gene is regulated at the level of transcriptional initiation and repressed by Mad1. Cancer research. 2000;60(8):2116-21. Epub 2000/04/29.

[55] Oh S, Song YH, Yim J, Kim TK. Identification of Mad as a repressor of the human telomerase (hTERT) gene. Oncogene. 2000;19(11):1485-90. Epub 2000/03/21.

[56] Xu D, Popov N, Hou M, Wang Q, Bjorkholm M, Gruber A, et al. Switch from Myc/Max to Mad1/Max binding and decrease in histone acetylation at the telomerase reverse transcriptase promoter during differentiation of HL60 cells. Proceedings of the National Academy of Sciences of the United States of America. 2001;98(7):3826-31. Epub 2001/03/29.

[57] Kyo S, Inoue M. Complex regulatory mechanisms of telomerase activity in normal and cancer cells: how can we apply them for cancer therapy? Oncogene. 2002;21(4):688-97. Epub 2002/02/19.

[58] Ohgaki H, Kleihues P. Genetic pathways to primary and secondary glioblastoma. The American journal of pathology. 2007;170(5):1445-53. Epub 2007/04/26.

[59] Yadav AK, Renfrow JJ, Scholtens DM, Xie H, Duran GE, Bredel C, et al. Monosomy of chromosome 10 associated with dysregulation of epidermal growth factor signaling in glioblastomas. JAMA : the journal of the American Medical Association. 2009;302(3):276-89. Epub 2009/07/16.

[60] Koul D. PTEN signaling pathways in glioblastoma. Cancer biology \& therapy. 2008;7(9):1321-5. Epub 2008/10/07. 
[61] Mellinghoff IK, Cloughesy TF, Mischel PS. PTEN-mediated resistance to epidermal growth factor receptor kinase inhibitors. Clinical cancer research : an official journal of the American Association for Cancer Research. 2007;13(2 Pt 1):378-81. Epub 2007/01/27.

[62] Bredel M, Scholtens DM, Yadav AK, Alvarez AA, Renfrow JJ, Chandler JP, et al. NFKBIA deletion in glioblastomas. The New England journal of medicine. 2011;364(7):627-37. Epub 2010/12/24.

[63] Veeriah S, Brennan C, Meng S, Singh B, Fagin JA, Solit DB, et al. The tyrosine phosphatase PTPRD is a tumor suppressor that is frequently inactivated and mutated in glioblastoma and other human cancers. Proceedings of the National Academy of Sciences of the United States of America. 2009;106(23):9435-40. Epub 2009/05/30.

[64] Wiedemeyer R, Brennan C, Heffernan TP, Xiao Y, Mahoney J, Protopopov A, et al. Feedback circuit among INK4 tumor suppressors constrains human glioblastoma development. Cancer cell. 2008;13(4):355-64. Epub 2008/04/09.

[65] Nakamura M, Yang F, Fujisawa H, Yonekawa Y, Kleihues P, Ohgaki H. Loss of heterozygosity on chromosome 19 in secondary glioblastomas. Journal of neuropathology and experimental neurology. 2000;59(6):539-43. Epub 2000/06/13.

[66] Bettegowda C, Agrawal N, Jiao Y, Sausen M, Wood LD, Hruban RH, et al. Mutations in CIC and FUBP1 contribute to human oligodendroglioma. Science. 2011;333(6048):14535. Epub 2011/08/06.

[67] Jenkins RB, Blair H, Ballman KV, Giannini C, Arusell RM, Law M, et al. A $t(1 ; 19)(q 10 ; p 10)$ mediates the combined deletions of $1 p$ and $19 q$ and predicts a better prognosis of patients with oligodendroglioma. Cancer research. 2006;66(20):9852-61. Epub 2006/10/19.

[68] Cairncross JG, Ueki K, Zlatescu MC, Lisle DK, Finkelstein DM, Hammond RR, et al. Specific genetic predictors of chemotherapeutic response and survival in patients with anaplastic oligodendrogliomas. Journal of the National Cancer Institute. 1998;90(19):1473-9. Epub 1998/10/17.

[69] Nakamura M, Ishida E, Shimada K, Kishi M, Nakase H, Sakaki T, et al. Frequent LOH on 22q12.3 and TIMP-3 inactivation occur in the progression to secondary glioblastomas. Laboratory investigation; a journal of technical methods and pathology. 2005;85(2):165-75. Epub 2004/12/14.

[70] Qi JH, Ebrahem Q, Moore N, Murphy G, Claesson-Welsh L, Bond M, et al. A novel function for tissue inhibitor of metalloproteinases-3 (TIMP3): inhibition of angiogenesis by blockage of VEGF binding to VEGF receptor-2. Nature medicine. 2003;9(4):407-15. Epub 2003/03/26.

[71] Bredel M, Scholtens DM, Harsh GR, Bredel C, Chandler JP, Renfrow JJ, et al. A network model of a cooperative genetic landscape in brain tumors. JAMA : the journal of the American Medical Association. 2009;302(3):261-75. Epub 2009/07/16.

[72] Vogelstein B, Fearon ER, Hamilton SR, Kern SE, Preisinger AC, Leppert M, et al. Genetic alterations during colorectal-tumor development. The New England journal of medicine. 1988;319(9):525-32. Epub 1988/09/01.

[73] Gladson CL, Prayson RA, Liu WM. The pathobiology of glioma tumors. Annual review of pathology. 2010;5:33-50. Epub 2009/09/10. 
[74] Salk JJ, Fox EJ, Loeb LA. Mutational heterogeneity in human cancers: origin and consequences. Annual review of pathology. 2010;5:51-75. Epub 2009/09/12.

[75] Zheng H, Ying H, Yan H, Kimmelman AC, Hiller DJ, Chen AJ, et al. p53 and Pten control neural and glioma stem/progenitor cell renewal and differentiation. Nature. 2008;455(7216):1129-33. Epub 2008/10/25.

[76] Vivanco I, Rohle D, Versele M, Iwanami A, Kuga D, Oldrini B, et al. The phosphatase and tensin homolog regulates epidermal growth factor receptor (EGFR) inhibitor response by targeting EGFR for degradation. Proceedings of the National Academy of Sciences of the United States of America. 2010;107(14):6459-64. Epub 2010/03/24.

[77] Watanabe T, Yokoo H, Yokoo M, Yonekawa Y, Kleihues P, Ohgaki H. Concurrent inactivation of RB1 and TP53 pathways in anaplastic oligodendrogliomas. Journal of neuropathology and experimental neurology. 2001;60(12):1181-9. Epub 2002/01/05.

[78] Holland EC. Gliomagenesis: genetic alterations and mouse models. Nature reviews Genetics. 2001;2(2):120-9. Epub 2001/03/17.

[79] Ekstrand AJ, Sugawa N, James CD, Collins VP. Amplified and rearranged epidermal growth factor receptor genes in human glioblastomas reveal deletions of sequences encoding portions of the $\mathrm{N}$ - and/or C-terminal tails. Proceedings of the National Academy of Sciences of the United States of America. 1992;89(10):4309-13. Epub 1992/05/15.

[80] Nishikawa R, Sugiyama T, Narita Y, Furnari F, Cavenee WK, Matsutani M. Immunohistochemical analysis of the mutant epidermal growth factor, deltaEGFR, in glioblastoma. Brain tumor pathology. 2004;21(2):53-6. Epub 2005/02/11.

[81] Inda MM, Bonavia R, Mukasa A, Narita Y, Sah DW, Vandenberg S, et al. Tumor heterogeneity is an active process maintained by a mutant EGFR-induced cytokine circuit in glioblastoma. Genes \& development. 2010;24(16):1731-45. Epub 2010/08/18.

[82] Lee JC, Vivanco I, Beroukhim R, Huang JH, Feng WL, DeBiasi RM, et al. Epidermal growth factor receptor activation in glioblastoma through novel missense mutations in the extracellular domain. PLoS medicine. 2006;3(12):e485. Epub 2006/12/21.

[83] Paez JG, Janne PA, Lee JC, Tracy S, Greulich H, Gabriel S, et al. EGFR mutations in lung cancer: correlation with clinical response to gefitinib therapy. Science. 2004; 304(5676):1497-500. Epub 2004/05/01.

[84] Lynch TJ, Bell DW, Sordella R, Gurubhagavatula S, Okimoto RA, Brannigan BW, et al. Activating mutations in the epidermal growth factor receptor underlying responsiveness of non-small-cell lung cancer to gefitinib. The New England journal of medicine. 2004;350(21):2129-39. Epub 2004/05/01.

[85] Yuan TL, Cantley LC. PI3K pathway alterations in cancer: variations on a theme. Oncogene. 2008;27(41):5497-510. Epub 2008/09/17.

[86] Soroceanu L, Kharbanda S, Chen R, Soriano RH, Aldape K, Misra A, et al. Identification of IGF2 signaling through phosphoinositide-3-kinase regulatory subunit 3 as a growthpromoting axis in glioblastoma. Proceedings of the National Academy of Sciences of the United States of America. 2007;104(9):3466-71. Epub 2007/03/16.

[87] Sun M, Hillmann P, Hofmann BT, Hart JR, Vogt PK. Cancer-derived mutations in the regulatory subunit p85alpha of phosphoinositide 3-kinase function through the 
catalytic subunit p110alpha. Proceedings of the National Academy of Sciences of the United States of America. 2010;107(35):15547-52. Epub 2010/08/18.

[88] Knobbe CB, Reifenberger J, Reifenberger G. Mutation analysis of the Ras pathway genes NRAS, HRAS, KRAS and BRAF in glioblastomas. Acta neuropathologica. 2004;108(6):467-70. Epub 2004/11/02.

[89] Walker L, Thompson D, Easton D, Ponder B, Ponder M, Frayling I, et al. A prospective study of neurofibromatosis type 1 cancer incidence in the UK. British journal of cancer. 2006;95(2):233-8. Epub 2006/06/21.

[90] McGillicuddy LT, Fromm JA, Hollstein PE, Kubek S, Beroukhim R, De Raedt T, et al. Proteasomal and genetic inactivation of the NF1 tumor suppressor in gliomagenesis. Cancer cell. 2009;16(1):44-54. Epub 2009/07/04.

[91] Zhu Y, Harada T, Liu L, Lush ME, Guignard F, Harada C, et al. Inactivation of NF1 in CNS causes increased glial progenitor proliferation and optic glioma formation. Development. 2005;132(24):5577-88. Epub 2005/11/30.

[92] Kanu OO, Hughes B, Di C, Lin N, Fu J, Bigner DD, et al. Glioblastoma Multiforme Oncogenomics and Signaling Pathways. Clinical medicine Oncology. 2009;3:39-52. Epub 2009/09/25.

[93] Fulci G, Labuhn M, Maier D, Lachat Y, Hausmann O, Hegi ME, et al. p53 gene mutation and ink4a-arf deletion appear to be two mutually exclusive events in human glioblastoma. Oncogene. 2000;19(33):3816-22. Epub 2000/08/19.

[94] He J, Olson JJ, James CD. Lack of p16INK4 or retinoblastoma protein ( $\mathrm{pRb}$ ), or amplification-associated overexpression of cdk4 is observed in distinct subsets of malignant glial tumors and cell lines. Cancer research. 1995;55(21):4833-6. Epub 1995/11/01.

[95] Ishii N, Maier D, Merlo A, Tada M, Sawamura Y, Diserens AC, et al. Frequent coalterations of TP53, p16/CDKN2A, p14ARF, PTEN tumor suppressor genes in human glioma cell lines. Brain Pathol. 1999;9(3):469-79. Epub 1999/07/23.

[96] Louis DN. The p53 gene and protein in human brain tumors. Journal of neuropathology and experimental neurology. 1994;53(1):11-21. Epub 1994/01/01.

[97] Nozaki M, Tada M, Kobayashi H, Zhang CL, Sawamura Y, Abe H, et al. Roles of the functional loss of p53 and other genes in astrocytoma tumorigenesis and progression. Neuro-oncology. 1999;1(2):124-37. Epub 2001/09/12.

[98] Vousden KH, Prives C. Blinded by the Light: The Growing Complexity of p53. Cell. 2009;137(3):413-31. Epub 2009/05/05.

[99] Zhao T, Xu Y. p53 and stem cells: new developments and new concerns. Trends in cell biology. 2010;20(3):170-5. Epub 2010/01/12.

[100] Masui K, Cloughesy TF, Mischel PS. Review: molecular pathology in adult high-grade gliomas: from molecular diagnostics to target therapies. Neuropathology and applied neurobiology. 2012;38(3):271-91. Epub 2011/11/22.

[101] Hulleman E, Helin K. Molecular mechanisms in gliomagenesis. Advances in cancer research. 2005;94:1-27. Epub 2005/08/13.

[102] Furnari FB, Fenton T, Bachoo RM, Mukasa A, Stommel JM, Stegh A, et al. Malignant astrocytic glioma: genetics, biology, and paths to treatment. Genes \& development. 2007;21(21):2683-710. Epub 2007/11/03. 
[103] Schiebe M, Ohneseit P, Hoffmann W, Meyermann R, Rodemann HP, Bamberg M. Analysis of $\mathrm{mdm} 2$ and p53 gene alterations in glioblastomas and its correlation with clinical factors. Journal of neuro-oncology. 2000;49(3):197-203. Epub 2001/02/24.

[104] Birner P, Piribauer M, Fischer I, Gatterbauer B, Marosi C, Ungersbock K, et al. Prognostic relevance of p53 protein expression in glioblastoma. Oncology reports. 2002;9(4):703-7. Epub 2002/06/18.

[105] Kraus JA, Glesmann N, Beck M, Krex D, Klockgether T, Schackert G, et al. Molecular analysis of the PTEN, TP53 and CDKN2A tumor suppressor genes in long-term survivors of glioblastoma multiforme. Journal of neuro-oncology. 2000;48(2):89-94. Epub 2000/11/18.

[106] Kraus JA, Wenghoefer M, Glesmann N, Mohr S, Beck M, Schmidt MC, et al. TP53 gene mutations, nuclear p53 accumulation, expression of Waf/p21, Bcl-2, and CD95 (APO$1 /$ Fas) proteins are not prognostic factors in de novo glioblastoma multiforme. Journal of neuro-oncology. 2001;52(3):263-72. Epub 2001/08/25.

[107] Stark AM, Hugo HH, Witzel P, Mihajlovic Z, Mehdorn HM. Age-related expression of p53, Mdm2, EGFR and Msh2 in glioblastoma multiforme. Zentralblatt fur Neurochirurgie. 2003;64(1):30-6. Epub 2003/02/13.

[108] Newcomb EW, Cohen H, Lee SR, Bhalla SK, Bloom J, Hayes RL, et al. Survival of patients with glioblastoma multiforme is not influenced by altered expression of $\mathrm{p} 16$, p53, EGFR, MDM2 or Bcl-2 genes. Brain Pathol. 1998;8(4):655-67. Epub 1998/11/06.

[109] Rolhion C, Penault-Llorca F, Kemeny JL, Kwiatkowski F, Lemaire JJ, Chollet P, et al. $\mathrm{O}(6)$-methylguanine-DNA methyltransferase gene (MGMT) expression in human glioblastomas in relation to patient characteristics and p53 accumulation. International ournal of cancer Journal international du cancer. 1999;84(4):416-20. Epub 1999/07/15.

[110] Criniere E, Kaloshi G, Laigle-Donadey F, Lejeune J, Auger N, Benouaich-Amiel A, et al. MGMT prognostic impact on glioblastoma is dependent on therapeutic modalities. Journal of neuro-oncology. 2007;83(2):173-9. Epub 2007/01/16.

[111] Puduvalli VK, Kyritsis AP, Hess KR, Bondy ML, Fuller GN, Kouraklis GP, et al. Patterns of expression of $\mathrm{Rb}$ and $\mathrm{p} 16$ in astrocytic gliomas, and correlation with survival. International journal of oncology. 2000;17(5):963-9. Epub 2000/10/13.

[112] Backlund LM, Nilsson BR, Liu L, Ichimura K, Collins VP. Mutations in Rb1 pathwayrelated genes are associated with poor prognosis in anaplastic astrocytomas. British ournal of cancer. 2005;93(1):124-30. Epub 2005/06/23.

[113] Ang C, Guiot MC, Ramanakumar AV, Roberge D, Kavan P. Clinical significance of molecular biomarkers in glioblastoma. The Canadian journal of neurological sciences Le ournal canadien des sciences neurologiques. 2010;37(5):625-30. Epub 2010/11/10.

[114] Bleeker FE, Lamba S, Leenstra S, Troost D, Hulsebos T, Vandertop WP, et al. IDH1 mutations at residue p.R132 (IDH1(R132)) occur frequently in high-grade gliomas but not in other solid tumors. Human mutation. 2009;30(1):7-11. Epub 2009/01/02.

[115] Sanson M, Marie Y, Paris S, Idbaih A, Laffaire J, Ducray F, et al. Isocitrate dehydrogenase 1 codon 132 mutation is an important prognostic biomarker in gliomas. Journal of clinical oncology : official journal of the American Society of Clinical Oncology. 2009;27(25):4150-4. Epub 2009/07/29. 
[116] Nobusawa S, Watanabe T, Kleihues P, Ohgaki H. IDH1 mutations as molecular signature and predictive factor of secondary glioblastomas. Clinical cancer research : an official journal of the American Association for Cancer Research. 2009;15(19):6002-7. Epub 2009/09/17.

[117] Ichimura K, Pearson DM, Kocialkowski S, Backlund LM, Chan R, Jones DT, et al. IDH1 mutations are present in the majority of common adult gliomas but rare in primary glioblastomas. Neuro-oncology. 2009;11(4):341-7. Epub 2009/05/14.

[118] Balss J, Meyer J, Mueller W, Korshunov A, Hartmann C, von Deimling A. Analysis of the IDH1 codon 132 mutation in brain tumors. Acta neuropathologica. 2008;116(6):597602. Epub 2008/11/06.

[119] Hartmann C, Meyer J, Balss J, Capper D, Mueller W, Christians A, et al. Type and frequency of IDH1 and IDH2 mutations are related to astrocytic and oligodendroglial differentiation and age: a study of 1,010 diffuse gliomas. Acta neuropathologica. 2009;118(4):469-74. Epub 2009/06/26.

[120] Yan H, Parsons DW, Jin G, McLendon R, Rasheed BA, Yuan W, et al. IDH1 and IDH2 mutations in gliomas. The New England journal of medicine. 2009;360(8):765-73. Epub 2009/02/21.

[121] Hartmann C, Hentschel B, Wick W, Capper D, Felsberg J, Simon M, et al. Patients with IDH1 wild type anaplastic astrocytomas exhibit worse prognosis than IDH1-mutated glioblastomas, and IDH1 mutation status accounts for the unfavorable prognostic effect of higher age: implications for classification of gliomas. Acta neuropathologica. 2010;120(6):707-18. Epub 2010/11/23.

[122] Dang L, White DW, Gross S, Bennett BD, Bittinger MA, Driggers EM, et al. Cancerassociated IDH1 mutations produce 2-hydroxyglutarate. Nature. 2009;462(7274):739-44. Epub 2009/11/26.

[123] Loenarz C, Schofield CJ. Expanding chemical biology of 2-oxoglutarate oxygenases. Nature chemical biology. 2008;4(3):152-6. Epub 2008/02/19.

[124] Xu W, Yang H, Liu Y, Yang Y, Wang P, Kim SH, et al. Oncometabolite 2hydroxyglutarate is a competitive inhibitor of alpha-ketoglutarate-dependent dioxygenases. Cancer cell. 2011;19(1):17-30. Epub 2011/01/22.

[125] Turcan S, Rohle D, Goenka A, Walsh LA, Fang F, Yilmaz E, et al. IDH1 mutation is sufficient to establish the glioma hypermethylator phenotype. Nature. 2012;483(7390):479-83. Epub 2012/02/22.

[126] Figueroa ME, Abdel-Wahab O, Lu C, Ward PS, Patel J, Shih A, et al. Leukemic IDH1 and IDH2 mutations result in a hypermethylation phenotype, disrupt TET2 function, and impair hematopoietic differentiation. Cancer cell. 2010;18(6):553-67. Epub 2010/12/07.

[127] Watanabe T, Nobusawa S, Kleihues P, Ohgaki H. IDH1 mutations are early events in the development of astrocytomas and oligodendrogliomas. The American journal of pathology. 2009;174(4):1149-53. Epub 2009/02/28.

[128] Lai A, Kharbanda S, Pope WB, Tran A, Solis OE, Peale F, et al. Evidence for sequenced molecular evolution of IDH1 mutant glioblastoma from a distinct cell of origin. Journal of clinical oncology : official journal of the American Society of Clinical Oncology. 2011;29(34):4482-90. Epub 2011/10/26. 
[129] Sepulveda AR, Jones D, Ogino S, Samowitz W, Gulley ML, Edwards R, et al. CpG methylation analysis--current status of clinical assays and potential applications in molecular diagnostics: a report of the Association for Molecular Pathology. The Journal of molecular diagnostics : JMD. 2009;11(4):266-78. Epub 2009/06/23.

[130] Milbury CA, Chen CC, Mamon H, Liu P, Santagata S, Makrigiorgos GM. Multiplex amplification coupled with COLD-PCR and high resolution melting enables identification of low-abundance mutations in cancer samples with low DNA content. The Journal of molecular diagnostics : JMD. 2011;13(2):220-32. Epub 2011/03/01.

[131] Mattick JS, Makunin IV. Non-coding RNA. Human molecular genetics. 2006;15 Spec No 1:R17-29. Epub 2006/05/03.

[132] Nagarajan RP, Costello JF. Epigenetic mechanisms in glioblastoma multiforme. Seminars in cancer biology. 2009;19(3):188-97. Epub 2009/05/12.

[133] Clark SJ, Harrison J, Frommer M. CpNpG methylation in mammalian cells. Nature genetics. 1995;10(1):20-7. Epub 1995/05/01.

[134] Turner BM. Reading signals on the nucleosome with a new nomenclature for modified histones. Nature structural \& molecular biology. 2005;12(2):110-2. Epub 2005/02/11.

[135] Bartek J, Jr., Ng K, Bartek J, Fischer W, Carter B, Chen CC. Key concepts in glioblastoma therapy. Journal of neurology, neurosurgery, and psychiatry. 2012;83(7):753-60. Epub 2012/03/08.

[136] Tano K, Shiota S, Collier J, Foote RS, Mitra S. Isolation and structural characterization of a cDNA clone encoding the human DNA repair protein for O6-alkylguanine. Proceedings of the National Academy of Sciences of the United States of America. 1990;87(2):686-90. Epub 1990/01/01.

[137] Hegi ME, Liu L, Herman JG, Stupp R, Wick W, Weller M, et al. Correlation of O6methylguanine methyltransferase (MGMT) promoter methylation with clinical outcomes in glioblastoma and clinical strategies to modulate MGMT activity. Journal of clinical oncology : official journal of the American Society of Clinical Oncology. 2008;26(25):4189-99. Epub 2008/09/02.

[138] Mikeska T, Bock C, El-Maarri O, Hubner A, Ehrentraut D, Schramm J, et al. Optimization of quantitative MGMT promoter methylation analysis using pyrosequencing and combined bisulfite restriction analysis. The Journal of molecular diagnostics : JMD. 2007;9(3):368-81. Epub 2007/06/27.

[139] Herfarth KK, Brent TP, Danam RP, Remack JS, Kodner IJ, Wells SA, Jr., et al. A specific CPG methylation pattern of the MGMT promoter region associated with reduced MGMT expression in primary colorectal cancers. Molecular carcinogenesis. 1999;24(2):90-8. Epub 1999/03/17.

[140] Watts GS, Pieper RO, Costello JF, Peng YM, Dalton WS, Futscher BW. Methylation of discrete regions of the O6-methylguanine DNA methyltransferase (MGMT) CpG island is associated with heterochromatinization of the MGMT transcription start site and silencing of the gene. Molecular and cellular biology. 1997;17(9):5612-9. Epub 1997/09/01.

[141] Hegi ME, Diserens AC, Gorlia T, Hamou MF, de Tribolet N, Weller M, et al. MGMT gene silencing and benefit from temozolomide in glioblastoma. The New England ournal of medicine. 2005;352(10):997-1003. Epub 2005/03/11. 
[142] Rivera AL, Pelloski CE, Gilbert MR, Colman H, De La Cruz C, Sulman EP, et al. MGMT promoter methylation is predictive of response to radiotherapy and prognostic in the absence of adjuvant alkylating chemotherapy for glioblastoma. Neuro-oncology. 2010;12(2):116-21. Epub 2010/02/13.

[143] Nitta M, Kozono D, Kennedy R, Stommel J, Ng K, Zinn PO, et al. Targeting EGFR induced oxidative stress by PARP1 inhibition in glioblastoma therapy. PloS one. 2010;5(5):e10767. Epub 2010/06/10.

[144] Noushmehr H, Weisenberger DJ, Diefes K, Phillips HS, Pujara K, Berman BP, et al. Identification of a $\mathrm{CpG}$ island methylator phenotype that defines a distinct subgroup of glioma. Cancer cell. 2010;17(5):510-22. Epub 2010/04/20.

[145] Orkin SH, Hochedlinger K. Chromatin connections to pluripotency and cellular reprogramming. Cell. 2011;145(6):835-50. Epub 2011/06/15.

[146] Zheng D, Frankish A, Baertsch R, Kapranov P, Reymond A, Choo SW, et al. Pseudogenes in the ENCODE regions: consensus annotation, analysis of transcription, and evolution. Genome research. 2007;17(6):839-51. Epub 2007/06/15.

[147] Hasler J, Samuelsson T, Strub K. Useful 'junk': Alu RNAs in the human transcriptome. Cellular and molecular life sciences : CMLS. 2007;64(14):1793-800. Epub 2007/05/22.

[148] Lander ES, Linton LM, Birren B, Nusbaum C, Zody MC, Baldwin J, et al. Initial sequencing and analysis of the human genome. Nature. 2001;409(6822):860-921. Epub 2001/03/10.

[149] Tso CL, Freije WA, Day A, Chen Z, Merriman B, Perlina A, et al. Distinct transcription profiles of primary and secondary glioblastoma subgroups. Cancer research. 2006;66(1):159-67. Epub 2006/01/07.

[150] Furuta M, Weil RJ, Vortmeyer AO, Huang S, Lei J, Huang TN, et al. Protein patterns and proteins that identify subtypes of glioblastoma multiforme. Oncogene. 2004;23(40):6806-14. Epub 2004/08/03.

[151] Kim TM, Huang W, Park R, Park PJ, Johnson MD. A developmental taxonomy of glioblastoma defined and maintained by MicroRNAs. Cancer research. 2011;71(9):338799. Epub 2011/03/10.

[152] Gunther HS, Schmidt NO, Phillips HS, Kemming D, Kharbanda S, Soriano R, et al. Glioblastoma-derived stem cell-enriched cultures form distinct subgroups according to molecular and phenotypic criteria. Oncogene. 2008;27(20):2897-909. Epub 2007/11/27.

[153] Carro MS, Lim WK, Alvarez MJ, Bollo RJ, Zhao X, Snyder EY, et al. The transcriptional network for mesenchymal transformation of brain tumours. Nature. 2010;463(7279):31825. Epub 2009/12/25.

[154] Iwamoto FM, Hottinger AF, Karimi S, Riedel E, Dantis J, Jahdi M, et al. Serum YKL-40 is a marker of prognosis and disease status in high-grade gliomas. Neuro-oncology. 2011;13(11):1244-51. Epub 2011/08/13.

[155] Santosh V, Arivazhagan A, Sreekanthreddy P, Srinivasan H, Thota B, Srividya MR, et al. Grade-specific expression of insulin-like growth factor-binding proteins-2, -3 , and -5 in astrocytomas: IGFBP-3 emerges as a strong predictor of survival in patients with newly diagnosed glioblastoma. Cancer epidemiology, biomarkers \& prevention : a publication of the American Association for Cancer Research, cosponsored by the American Society of Preventive Oncology. 2010;19(6):1399-408. Epub 2010/05/27. 
[156] Godard S, Getz G, Delorenzi M, Farmer P, Kobayashi H, Desbaillets I, et al. Classification of human astrocytic gliomas on the basis of gene expression: a correlated group of genes with angiogenic activity emerges as a strong predictor of subtypes. Cancer research. 2003;63(20):6613-25. Epub 2003/10/30.

[157] Nigro JM, Misra A, Zhang L, Smirnov I, Colman H, Griffin C, et al. Integrated arraycomparative genomic hybridization and expression array profiles identify clinically relevant molecular subtypes of glioblastoma. Cancer research. 2005;65(5):1678-86. Epub 2005/03/09.

[158] Hormigo A, Gu B, Karimi S, Riedel E, Panageas KS, Edgar MA, et al. YKL-40 and matrix metalloproteinase- 9 as potential serum biomarkers for patients with high-grade gliomas. Clinical cancer research : an official journal of the American Association for Cancer Research. 2006;12(19):5698-704. Epub 2006/10/06.

[159] Tso CL, Shintaku P, Chen J, Liu Q, Liu J, Chen Z, et al. Primary glioblastomas express mesenchymal stem-like properties. Molecular cancer research : MCR. 2006;4(9):607-19. Epub 2006/09/13.

[160] Lee Y, Scheck AC, Cloughesy TF, Lai A, Dong J, Farooqi HK, et al. Gene expression analysis of glioblastomas identifies the major molecular basis for the prognostic benefit of younger age. BMC medical genomics. 2008;1:52. Epub 2008/10/23.

[161] Colman H, Zhang L, Sulman EP, McDonald JM, Shooshtari NL, Rivera A, et al. A multigene predictor of outcome in glioblastoma. Neuro-oncology. 2010;12(1):49-57. Epub 2010/02/13.

[162] Yogev O, Lagos D. Noncoding RNAs and cancer. Silence. 2011;2(1):6. Epub 2011/10/01.

[163] Fowler A, Thomson D, Giles K, Maleki S, Mreich E, Wheeler H, et al. miR-124a is frequently down-regulated in glioblastoma and is involved in migration and invasion. Eur J Cancer. 2011;47(6):953-63. Epub 2011/01/05.

[164] Asadi-Moghaddam K, Chiocca EA, Lawler SE. Potential role of miRNAs and their inhibitors in glioma treatment. Expert review of anticancer therapy. 2010;10(11):1753-62. Epub 2010/11/18.

[165] Filipowicz W, Bhattacharyya SN, Sonenberg N. Mechanisms of post-transcriptional regulation by microRNAs: are the answers in sight? Nature reviews Genetics. 2008;9(2):102-14. Epub 2008/01/17.

[166] le Sage C, Nagel R, Egan DA, Schrier M, Mesman E, Mangiola A, et al. Regulation of the p27(Kip1) tumor suppressor by miR-221 and miR-222 promotes cancer cell proliferation. The EMBO journal. 2007;26(15):3699-708. Epub 2007/07/14.

[167] Guan Y, Mizoguchi M, Yoshimoto K, Hata N, Shono T, Suzuki SO, et al. MiRNA-196 is upregulated in glioblastoma but not in anaplastic astrocytoma and has prognostic significance. Clinical cancer research : an official journal of the American Association for Cancer Research. 2010;16(16):4289-97. Epub 2010/07/06.

[168] Kim H, Huang W, Jiang X, Pennicooke B, Park PJ, Johnson MD. Integrative genome analysis reveals an oncomir/oncogene cluster regulating glioblastoma survivorship. Proceedings of the National Academy of Sciences of the United States of America. 2010;107(5):2183-8. Epub 2010/01/19.

[169] Kefas B, Comeau L, Floyd DH, Seleverstov O, Godlewski J, Schmittgen T, et al. The neuronal microRNA miR-326 acts in a feedback loop with notch and has therapeutic 
potential against brain tumors. The Journal of neuroscience : the official journal of the Society for Neuroscience. 2009;29(48):15161-8. Epub 2009/12/04.

[170] Ciafre SA, Galardi S, Mangiola A, Ferracin M, Liu CG, Sabatino G, et al. Extensive modulation of a set of microRNAs in primary glioblastoma. Biochemical and biophysical research communications. 2005;334(4):1351-8. Epub 2005/07/26.

[171] Zhang CZ, Zhang JX, Zhang AL, Shi ZD, Han L, Jia ZF, et al. MiR-221 and miR-222 target PUMA to induce cell survival in glioblastoma. Molecular cancer. 2010;9:229. Epub 2010/09/04.

[172] Gabriely G, Yi M, Narayan RS, Niers JM, Wurdinger T, Imitola J, et al. Human glioma growth is controlled by microRNA-10b. Cancer research. 2011;71(10):3563-72. Epub 2011/04/08.

[173] Ma L, Teruya-Feldstein J, Weinberg RA. Tumour invasion and metastasis initiated by microRNA-10b in breast cancer. Nature. 2007;449(7163):682-8. Epub 2007/09/28.

[174] Calin GA, Liu CG, Sevignani C, Ferracin M, Felli N, Dumitru CD, et al. MicroRNA profiling reveals distinct signatures in B cell chronic lymphocytic leukemias. Proceedings of the National Academy of Sciences of the United States of America. 2004;101(32):11755-60. Epub 2004/07/31.

[175] Bloomston M, Frankel WL, Petrocca F, Volinia S, Alder H, Hagan JP, et al. MicroRNA expression patterns to differentiate pancreatic adenocarcinoma from normal pancreas and chronic pancreatitis. JAMA : the journal of the American Medical Association. 2007;297(17):1901-8. Epub 2007/05/03.

[176] Huse JT, Brennan C, Hambardzumyan D, Wee B, Pena J, Rouhanifard SH, et al. The PTEN-regulating microRNA miR-26a is amplified in high-grade glioma and facilitates gliomagenesis in vivo. Genes \& development. 2009;23(11):1327-37. Epub 2009/06/03.

[177] Poliseno L, Salmena L, Zhang J, Carver B, Haveman WJ, Pandolfi PP. A codingindependent function of gene and pseudogene mRNAs regulates tumour biology. Nature. 2010;465(7301):1033-8. Epub 2010/06/26.

[178] Godlewski J, Nowicki MO, Bronisz A, Williams S, Otsuki A, Nuovo G, et al. Targeting of the Bmi-1 oncogene/stem cell renewal factor by microRNA-128 inhibits glioma proliferation and self-renewal. Cancer research. 2008;68(22):9125-30. Epub 2008/11/18.

[179] Li KK, Pang JC, Ching AK, Wong CK, Kong X, Wang Y, et al. miR-124 is frequently down-regulated in medulloblastoma and is a negative regulator of SLC16A1. Human pathology. 2009;40(9):1234-43. Epub 2009/05/12.

[180] Furuta M, Kozaki KI, Tanaka S, Arii S, Imoto I, Inazawa J. miR-124 and miR-203 are epigenetically silenced tumor-suppressive microRNAs in hepatocellular carcinoma. Carcinogenesis. 2010;31(5):766-76. Epub 2009/10/22.

[181] Silber J, Lim DA, Petritsch C, Persson AI, Maunakea AK, Yu M, et al. miR-124 and miR-137 inhibit proliferation of glioblastoma multiforme cells and induce differentiation of brain tumor stem cells. BMC medicine. 2008;6:14. Epub 2008/06/26.

[182] Gal H, Pandi G, Kanner AA, Ram Z, Lithwick-Yanai G, Amariglio N, et al. MIR-451 and Imatinib mesylate inhibit tumor growth of Glioblastoma stem cells. Biochemical and biophysical research communications. 2008;376(1):86-90. Epub 2008/09/04. 
[183] Sana J, Hajduch M, Michalek J, Vyzula R, Slaby O. MicroRNAs and glioblastoma: roles in core signalling pathways and potential clinical implications. Journal of cellular and molecular medicine. 2011;15(8):1636-44. Epub 2011/03/26.

[184] Ziegler DS, Wright RD, Kesari S, Lemieux ME, Tran MA, Jain M, et al. Resistance of human glioblastoma multiforme cells to growth factor inhibitors is overcome by blockade of inhibitor of apoptosis proteins. The Journal of clinical investigation. 2008;118(9):3109-22. Epub 2008/08/05.

[185] Slaby O, Lakomy R, Fadrus P, Hrstka R, Kren L, Lzicarova E, et al. MicroRNA-181 family predicts response to concomitant chemoradiotherapy with temozolomide in glioblastoma patients. Neoplasma. 2010;57(3):264-9. Epub 2010/04/01.

[186] Zhang W, Zhang J, Hoadley K, Kushwaha D, Ramakrishnan V, Li S, et al. miR-181d: a predictive glioblastoma biomarker that downregulates MGMT expression. Neurooncology. 2012;14(6):712-9. Epub 2012/05/10. 